\title{
Assessment of MODIS spectral indices for determining rice paddy agricultural practices and hydroperiod
}

\author{
Lucia Tornos $^{\mathrm{a}, *}$, Margarita Huesca ${ }^{\mathrm{b}}$, Jose Antonio Dominguez ${ }^{\mathrm{c}}$, Maria Carmen Moyano ${ }^{\mathrm{a}}$, \\ Victor Cicuendez ${ }^{\mathrm{d}}$, Laura Recuero ${ }^{\mathrm{d}}$, Alicia Palacios-Orueta ${ }^{\mathrm{d}}$ \\ ${ }^{a}$ Centre for Hydrographic Studies, CEDEX, Spain \\ ${ }^{\mathrm{b}}$ Center for Spatial Technologies and Remote Sensing (CSTARS), Department of Land, Air, and Water Resources, University of California, Davis, United States \\ ${ }^{\mathrm{c}}$ The National Distance Education University, UNED, Spain \\ ${ }^{\mathrm{d}}$ Departamento de Silvopascicultura, ETSIM, Universidad Politécnica de Madrid, Spain
}

\section{A R T I C L E I N F O}

\section{Keywords:}

Agriculture

Monitoring

MODIS

Vegetation

Detection

Analysis

Floods

Crop

\begin{abstract}
A B S T R A C T
Rice agricultural practices and hydroperiod dates must be determined to obtain information on water management practices and their environmental effects. Spectral indices derived from an 8-day MODIS composite allows to identify rice phenometrics at varying degrees of success. The aims of this study were (1) to assess the dynamics of the Normalized Difference Vegetation Index (NDVI), Normalized Difference Water Index (NDWI(1) and NDWI(2)) and Shortwave Angle Slope Index (SASI) in relation to rice agricultural practices and hydroperiod, and (2) to assess the capability for these indices to detect phenometrics in rice under different flooding regimes. Two rice farming areas in Spain that are governed under different water management practices, the Ebro Delta and Orellana, were studied over a 12-year period (2001-2012). The index time series autocorrelation function was calculated to determine index dynamics in both areas. Secondly, average indices were calculated to identify significant points close to key agricultural and flooding dates, and index behaviors and capacities to identify phenometrics were assessed on a pixel level. The index autocorrelation function produced a regular pattern in both zones, being remarkably homogeneous in the Ebro Delta. It was concluded that a combination of NDVI, NDWI(1), NDWI(2) and SASI may improve the results obtained through each index. NDVI was more effective at detecting the heading date and flooding trends in the Ebro Delta. NDWI(1), NDWI(2) and SASI identified the harvest and the end of environmental flooding in the Delta, and the flooding in Orellana, more effectively. These results may set strong foundations for the development of new strategies in rice monitoring systems, providing useful information to policy makers and environmental studies.
\end{abstract}

\section{Introduction}

Approximately 180 million ha are under rice cultivation worldwide, and 475,000 ha are located in the European Union (MAGRAMA, 2013). Sustainable rice farming plays a key role in food security; according to the United Nations, more than $50 \%$ of the global population depends on rice for approximately $80 \%$ of its food requirements (FAO, 2002). Moreover, rice fields represent an important aquatic ecosystem, hosting a large variety of terrestrial and aquatic species (FAO, 2013) that typically remain flooded during the growing season. Despite the positive functions of rice

\footnotetext{
* Corresponding author at: Centre for Hydrographic Studies, CEDEX, Paseo bajo de la Virgen del Puerto 3, 28005 Madrid, Spain.

E-mail address: luciatornos@gmail.com (L. Tornos).
}

systems, such systems also cause environmental degradation (Van Niel and McVicar, 2004). Rice water consumption and greenhouse gas emissions from paddy fields are especially critical issues (FAO, 2013). In upcoming years, the world will face the challenge of meeting global demands for rice while preserving land and water resources. Thus, monitoring these systems will become essential at both the local and global scale (Kerr and Ostrovsky, 2003).

Phenological data are used to estimate net primary production (Kimball et al., 2004), crop growth and yield (Bauman et al., 2001). These data may also be used to determine time boundary conditions in crop yield models (Bauman et al., 2001), to examine animal dynamics in crop-associated fauna (Pettorelli et al., 2005) and to support water management decisions (Dingkuhn and Le Gal, 1996). Moreover, rice hydroperiod determination as part of the rice 
growing cycle is vital to rice monitoring and impact management and is expected to become more relevant in the near future (Torbick et al., 2011; Boschetti et al., 2014). This is particularly true in studies that examine rice paddy methane emissions (Xiao et al., 2005). The importance of rice water table depth and phenological fluctuations in methane (Meijide et al., 2011) illustrates the necessity to develop accurate rice agricultural and hydroperiod monitoring techniques.

Traditional studies focusing on phenology involve conducting on-site ground observations (Tang et al., 2009; Xu et al., 2012) and obtaining data at low temporal and spatial scales (Pettorelli et al., 2005). The growing importance of spatial and temporal continuous data in these studies (Delbart et al., 2005) has made remote sensing increasingly relevant, as this approach allows for large-scale and frequent sampling (Zhang et al., 2003). Advances in geospatial technology and remote sensing will further increase the relevance of such methods to agroecosystems management and monitoring by raising productivity and reducing environmental degradation (Van Niel and McVicar, 2004).

Remote sensing has proved to be instrumental to the monitoring of rice agricultural production (Lopez-Sanchez et al., 2011; Gumma et al., 2014) and flooding (Moré et al., 2011; Son et al., 2013; Boschetti et al., 2014) at both regional and global scales. One of the first space borne multispectral sensors developed for rice monitoring is the Landsat Multiespectral Scanner (MSS) (Ustin, 2004). Providing a spatial resolution of $30 \mathrm{~m}$, Landsat images are frequently used in rice studies (Oguro et al., 2001; Báez-González et al., 2002; Moré et al., 2011; Li et al., 2012). Other sensors such as the NOAA Advanced Very High Resolution Radiometer (AVHRR) and SPOT-4 VEGETATION generate daily low spatial resolution images ( $1 \mathrm{~km}$ ) (Xiao et al., 2002) and produce appropriate spectral bands that can be used in plant phenology studies. These sensors have been widely used for rice development monitoring in many studies (Fang et al., 1998; Kamthonkiat et al., 2005; Singh et al., 2006).

Launched in 1999, Moderate Resolution Imaging Spectroradiometer (MODIS) includes advantageous features of both the AVHRR and Landsat. The 8-day composite MODIS data product provides medium spatial resolution images $(500 \mathrm{~m})$ of adequate temporal resolution and improved atmospheric correction (Vermote and Vermeulen, 1999). MODIS includes seven bands that are designed to detect water and vegetation, which allows to study plant phenology (Delbart et al., 2005; Sari et al., 2010; Xu et al., 2012) and flooding (Ordoyne and Friedl, 2008).

The MODIS spectral index time series has been used in several studies for monitoring rice phenology and dynamics (Sakamoto et al., 2006; Motohka et al., 2009; Jacquin et al., 2010). Among spectral indices, the Normalized Vegetation Index (NDVI) and Enhanced Vegetation Index (EVI), which are based on photosynthetic activity, exhibit a good dynamic range and sensitivity for monitoring spatial and temporal variations in vegetation (Huete et al., 2002). The NDVI has been widely used in rice monitoring studies (Gumma et al., 2014). This index effectively detects heading dates (Boschetti et al., 2009; Wang et al., 2012) and shows sensitivity to soil wetness, making the tool suitable for monitoring irrigation start and padding (Motohka et al., 2009). EVI has also been used for rice crop monitoring and mapping (Xiao et al., 2005; Peng et al., 2011; Son et al., 2014). This index exhibits low sensitivity to vegetation canopy background variations and resists saturation in a dense canopy (Huete et al., 2002; Motohka et al., 2009). Thus, while EVI is more effective at avoiding saturation within a dense canopy, NDVI best detects soil condition changes (Motohka et al., 2009) while maintaining a suitable capacity to monitor rice phenology.

Spectral indices based on shortwave infrared bands have also been used to detect phenological events and rice hydroperiod
(Xiao et al., 2002; Boschetti et al., 2014). The Normalized Difference Water Index (NDWI(1)), which combines information included in the SWIR1 and NIR, is sensitive to soil and vegetation water response (Gao, 1996). The tool has proved useful in identifying vegetation statuses (Fensholt and Sandholt, 2003) and flooding events (Ordoyne and Friedl, 2008). Although this index was originally designed to detect vegetation water content, a number of works have also studied its effectiveness at monitoring surface water content (Boschetti et al., 2014). Additionally, NDWI(2), which combines SWIR2 and NIR bands, effectively detects significant increases in cropland surface water (Xiao et al., 2002) and monitors phenological stages (Delbart et al., 2005). Both of these capabilities (soil and vegetation water content detection) are essential to identify soil and crop water variations associated with rice phenology.

Other recent studies have demonstrated an interest in using new indices to characterize crop phenology and soil water content patterns (Das et al., 2013), as these indices can provide additional agricultural information that may be used to improve the results of other indices used separately. New approaches based on spectrum spectral shapes that combine angles formed by consecutive bands have been used successfully for this purpose in recent years (Palacios-Orueta et al., 2006). These new indices, referred to as Spectral Shape Indices (SSI), provide information of relationships between three consecutive bands, summarizing respective wavelength reflectance spectra. The Shortwave Angle Slope Index (SASI) (Khanna et al., 2007) in particular is based on the SWIR1 angle and is modified by including the slope between the NIR and SWIR2 reflectance. This index shows promising results in discriminating between land cover types and predicting soil and vegetation moisture content levels in laboratory and model simulated datasets. Das et al. (2013) illustrated the utility of SASI in determining soil wetness and dryness through threshold values, and PalaciosOrueta et al. (2012) used a modification of SASI, AS1, to monitor cotton key phenological stages. All these attributes make SASI potentially useful for detecting rice cycle dynamics: given its proved sensitivity to soil moisture changes, it may more effectively identify rice phenology and hydroperiod characteristics.

The monitoring of phenological crop stages and dynamics using spectral indices is frequently based on the derivation of time series phenological metrics (Sakamoto et al., 2005; Zhang and Xu, 2012), normally from NDVI, EVI and NDWI indices. These phenological metrics typically include transition dates such as the heading date (Boschetti et al., 2009; Wang et al., 2012), plant emergence and harvesting (Boschetti et al., 2009; Wu et al., 2010) and have been used with varying degrees of success. Methodologies applied for phenological metrics determination vary from the use of threshold values to the identification of maximum and minimum values. These studies focus on determining one or more phenometrics from one index or from a combination of indices (Sakamoto et al., 2005; Leinenkugel et al., 2013; Chumkesornkulkit et al., 2013).

Statistical time series analyses of data from multispectral sensors provide information on dynamics of crop growing patterns. In particular, the autocorrelation function (ACF) (Box et al., 1994) enables to conduct a quantitative evaluation of the stability of temporal patterns in terms of seasonality and periodicity, providing useful information of underlying processes (Dornelas et al., 2013). When used for crop monitoring, the ACF reveals meaningful information on crop dynamics and has been used to detect variations in cropping patterns (Setiawan et al., 2014). Therefore, a statistical approach based on the use of ACF for the study of spectral index time series may generate relevant information on vegetation and water dynamics.

Although several methodologies have been developed to explore specific phenometrics in rice and to provide tools for rice 
mapping, no definitive approach is used to identify all phenological stages present in rice systems (Boschetti et al., 2009), including hydroperiod. The availability of optical information in VIS-NIR and SWIR regions makes it possible to propose an integrative approach based on the use of an optimal combination of indices for improving the assessment of rice agricultural practices, crop dynamics and flooding management. An assessment of different indices in rice growing areas with different flooding regimes would set the basis for developing a complete detection tool for phenological stages and agro-practices adapted for particular rice systems. In addition, this approach (i.e., phenometrics) could be supplemented with information on general dynamics provided by temporal autocorrelation patterns.

The objective of this work was to assess the potential of different spectral indices for monitoring rice agricultural practices and hydroperiod dynamics by combining phenometrics and statistical time series approaches. Four spectral indices were tested: the $\operatorname{NDWI}(1), \operatorname{NDWI}(2)$ and SASI are based on the SWIR spectral region, and so they are related to water content, and the NDVI, based on photosynthetic activity, which is the most commonly used index in crop monitoring. This evaluation was focused on the study of their general dynamics and specific phenometrics. Based on the results obtained, a combination of indices was proposed. The analysis examined two rice-cropping areas that exhibit considerably different flooding regimes and which are governed under different management practices, thus resulting in different soil moisture and vegetation status dynamics.

The specific objectives of this study were:

(1) To assess and compare the seasonal stability of vegetation and water dynamics in the two zones through a statistical analysis of index time series over a 12-year period.

(2) To analyze MODIS indices behaviors (including SSI) in relation to rice growth stage and flooding characteristics, as well as the capability for these indices to monitor hydroperiod and agro-practices patterns in areas governed under different flooding regimes.

\section{Study areas and rice crop cycle: Ebro Delta and Orellana}

\subsection{The Ebro Delta}

The Ebro Delta, covering an area of 32,000 ha, is located along the north-eastern coast of the Iberian Peninsula (Fig. 1). The climate is Mediterranean, with an annual mean temperature of $18{ }^{\circ} \mathrm{C}$ and an annual mean rainfall level of $556 \mathrm{~mm}$. Croplands, protected wetlands and lagoons coexist in the area, and agricultural land, which is largely composed of rice fields, covers 21,500 ha. Rice paddies are flooded for nine months of the year to avoid salt level increases from the saline aquifer and to provide shelter and food for protected fauna. Rice field irrigation (flooding stage) roughly starts during the third week of April and involves complete flooding in two weeks. Water is driven by gravity through a network of irrigation canals and flows continuously into the rice fields. Drainage water is evacuated through surface drainage systems, managing field salinity and discharging the water into the sea and to surrounding lagoons.

The rice cycle lasts for between 120 and 140 days depending on the rice varieties involved and the interannual climatic fluctuations. Sowing occurs during the period between May 1st and May 15th. During the crop vegetative stage, which occurs between the sowing and heading date, significant structural development occurs due to leaf growth, and maximum biomass levels are reached at the heading date, which occurs roughly by late July. After the heading date, the reproductive stage begins, which is characterized by the development of rice panicles and a lack of vegetative growth. Over time, the crop wilts, and harvesting typically begins during the first week of September and is completed by the end of the month.

Rice fields are flooded again from the first week of October until mid-January in compliance with environmental measures agreed with farmers. Water levels during this environmental flooding period are lower than the typical $10 \mathrm{~cm}$ level maintained during the rice-flooding season, and these levels vary between fields. After the end of the environmental flooding stage, it takes nearly one month to drain the rice paddies. Depending on weather conditions, no water remains in the fields until the beginning of the next flooding season.

\subsection{Orellana}

The Orellana irrigated area is located close to the Guadiana River in the south-western region of the Iberian Peninsula (Fig. 2). The climate is Mediterranean with continental influences and scarce precipitation. Certain districts, including the 8500 ha area studied in this work, are nearly completely covered with rice paddies, as rice crops are one of the most economically relevant resources in this zone. The hydroperiod roughly begins during the last week of April, although this period may be delayed until approximately May 15th due to inadequate weather conditions. It should be noted that the process is not simultaneous. Rather, some areas are flooded before others. The fields are maintained at a water level of $5 \mathrm{~cm}$, with the exception of occasional variations due to specific agricultural management practices. Water applied to the fields percolates, discharges through a drainage network into tributary rivers, and finally flows into the Guadiana River.

The rice cycle in Orellana is similar to that of the Ebro Delta. However, as certain dates are shifted, the sowing date typically occurs one week later (roughly the second or third week of May). The heading date occurs during roughly the last week of July or beginning of August, and harvesting typically concludes by the first or second week of October, after which the fields remain bare and dry until the following rice season.

For the cases studied, we have defined the following stages:

Flooding (F) Flooding is defined as the period of time between the beginning of field flooding and complete flooding.

Heading date (HD) The heading date is defined as the range of dates during which panicle emergence is present in most rice fields.

Harvest (H) The harvest coincides with the end of the hydroperiod in Orellana. This crop stage is determined as the last harvesting date according to field data and is characterized by higher levels of interannual variability due to climatic conditions.

End of Environmental Flooding (EEF) This event specifically applies to the Ebro Delta and is defined as the date at which rice fields are completely drained. The length considered for this stage is longer, as field drainage is highly influenced by management practices.

A crop calendar detailing rice-flooding periods in both study areas is included in Table 1.

\section{Data sources}

The MOD09A1 dataset, which consists of an 8-day MODIS composite grid-level product at 500-meter spatial resolution, was acquired for the period of 2001-2012. The longest time series available was used to obtain average values of indices that adequately reflected the general behavior of the two zones. This dataset of 552 images contains reflectance values for Bands 1-7 (450 nm (Blue), $555 \mathrm{~nm}$ (Green), $645 \mathrm{~nm}$ (Red), $860 \mathrm{~nm}$ (NIR), 


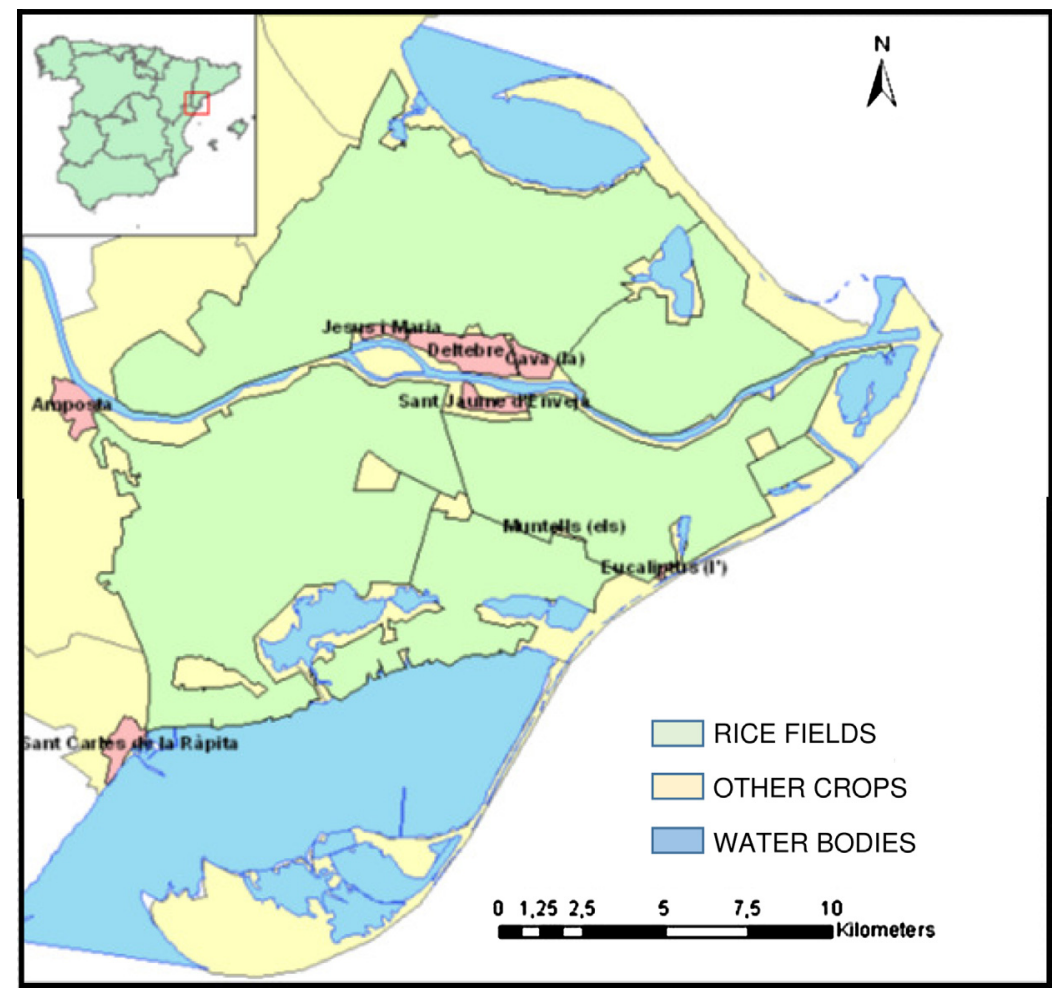

Fig. 1. Study area: The Ebro delta, Catalonia (Spain).

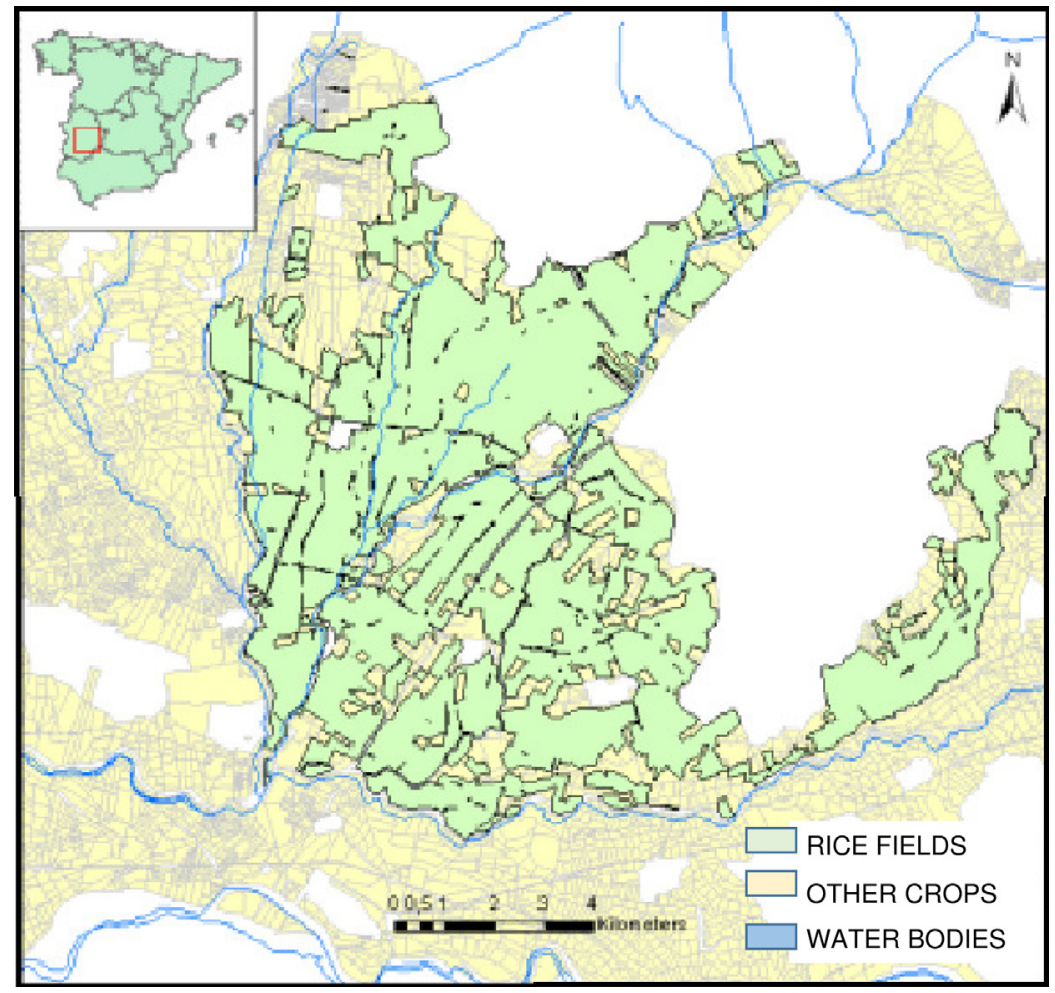

Fig. 2. Study area: Orellana, Extremadura (Spain).

$1240 \mathrm{~nm}$ (SWIR1), $1640 \mathrm{~nm}$ (SWIR2) and $2130 \mathrm{~nm}$ (SWIR3)), quality control flags, observation dates and sensor zenith angles per pixel. MOD09A1 products for the study areas were downloaded from the MODIS website (http://redhook.gsfc.nasa.gov/) and re-projected using the MODIS re-projection tool (http:// edc.usgs.gov/programs/sddm/modisdist/) to UTM zone 30. Quality flags were decoded using LDOPE. 
Table 1

Crop calendar and flooding stages for rice in the Ebro Delta and Orellana.

\begin{tabular}{|c|c|c|c|c|c|c|c|c|c|c|c|c|}
\hline & $\mathbf{J}$ & $\mathbf{F}$ & M & $\mathbf{A}$ & M & $\mathbf{J}$ & $\mathbf{J}$ & $\mathbf{A}$ & $\mathbf{S}$ & $\mathbf{O}$ & $\mathbf{N}$ & D \\
\hline Delta-rice & & & & & & & & & & & & \\
\hline Delta-flooding & & & & & & & & & & & & \\
\hline Orellana-rice & & & & & & & & & & & & \\
\hline Orellana-flooding & & & & & & & & & & & & \\
\hline
\end{tabular}

Crop calendars and descriptions of agricultural and water management practices were provided by water user associations based in both zones. The two selected areas are primarily devoted to rice cultivation, although a number of fields in Orellana include other crops, resulting in mixed pixels. Water management practices differ between the Delta and Orellana, and some phenological dates vary due to climatic differences. Although agricultural management practices are analogous, crops times vary between farmers. Digital crop maps for the studied areas were provided by the "Confederación Hidrográfica del Guadiana” (Ministry of Agriculture), CEDEX (Ministry of Public Works) and by water user associations.

\section{Methodology}

\subsection{Calculation of spectral indices}

In this study, NDVI, SASI (Khanna et al., 2007), NDWI(1) and $\operatorname{NDWI}(2)$, which is also known as Land Surface Water Index (Xiao et al., 2005), were used. NDVI was selected for its performance in detecting the heading date (Wang et al., 2012) and as a reference for the rest of the indices. We also applied NDWI(1) and NDWI(2), which are sensitive to leaf water and soil moisture (Xiao et al., 2005), as well as SASI, which is a shape index developed to distinguish among dry soil, wet soil, dry vegetation and green vegetation (Khanna et al., 2007). The first three indices are normalized difference indices that utilize surface reflectance values from the red, NIR, SWIR1 and SWIR2 bands, as described in Eqs. (1)-(3):

$\mathrm{NDVI}=\left(\rho_{\mathrm{NIR}}-\rho_{\mathrm{RED}}\right) /\left(\rho_{\mathrm{NIR}}+\rho_{\mathrm{RED}}\right)$

$\operatorname{NDWI}(1)=\left(\rho_{\mathrm{NIR}}-\rho_{\mathrm{SWIR} 1}\right) /\left(\rho_{\mathrm{NIR}}+\rho_{\mathrm{SWIR} 1}\right)$

$\operatorname{NDWI}(2)=\left(\rho_{\mathrm{NIR}}-\rho_{\mathrm{SWIR} 2}\right) /\left(\rho_{\mathrm{NIR}}+\rho_{\mathrm{SWIR} 2}\right)$

The last index listed is a spectral shape index (SSI), which is a variant of the SANI developed by Palacios-Orueta et al. (2006) and later modified by Khanna et al. (2007). SASI includes a combination of NIR, SWIR1 and SWIR2 MODIS bands and is based on the angle formed by the SWIR1 vertex with NIR and SWIR2 in the spectrum. The index explores the relationship between bands and coarsely emulates the behavior of this part of the spectrum. It is based on Whiting et al. (2004), which found a high correlation between the SWIR region and soil moisture. This index is defined by Khanna et al. (2007) as the product of the SWIR1 angle ( $\beta_{\text {SWIR1, }}$ Fig. 3) and the slope of line "c" that links reflectance $(R)$ at NIR and SWIR2 vertices (Fig. 3). The equations for calculating SASI are described in ((refspseqn 4$)-(6))$ below:

$\beta_{\mathrm{SWIR} 1}=\cos ^{-1}\left[\left(a^{2}+b^{2}-c^{2}\right) /\left(2^{*} a^{*} b\right)\right]$

Slope $=\left(R_{\text {SWIR2 }}-R_{\text {NIR }}\right) / d$

$\mathrm{SASI}=\beta_{\mathrm{SWIR} 1} *$ Slope
In general terms, slope $\mathrm{c}$ is positive for dry soils and decreases for wet soils. Vegetation residue and dry vegetation hold a slope close to zero, and green vegetation generates negative values. The value of angle $\beta_{\text {SWIR1 }}$, which is also referred to as AS1, is typically large for green vegetation and dry soils, and smaller for wet soils and dry vegetation. Thus, the product of the angle and slope is positive and large for dry soils, and negative and large for green vegetation. For dry matter, SASI is close to zero, as both the angle and the slope are small. In wet soils, the index is positive but small due to a decrease in $\beta_{\text {SWIR1. }}$

The time series for each reflectance band were compiled, and the indices were calculated for the whole study period using ENVI4.5.

Many rice phenological studies that use MODIS indices apply noise-filtering techniques to the data time-series (Boschetti et al., 2009; Son et al., 2014) due to abnormal values caused by certain atmospheric conditions (Chen et al., 2004). In this work, low quality pixel values were eliminated based on MODIS quality data bands, and cloud-contaminated pixels were removed based on the internal cloud algorithm flag of MOD09A1.005 500-meter Surface Reflectance Data State QA. Other outliers were identified as values falling outside the range of the mean plus/minus twice the standard deviation within a five-date period window. Missing data were replaced with the average of the previous and subsequent date values in the time series.

\subsection{Data analysis}

\subsubsection{Statistical time series analysis}

The dynamics of indices of both study sites for the period 20012012 were first assessed by means of the autocorrelation function (ACF) of the time series. The ACF provides a measure for the correlation of a variable with itself at different time lags. As a mathematical tool, it identifies either repetitive patterns or the presence of periodic components in a time series, generating information that may be obscured by noise (Box et al., 1994).

The time series autocorrelation function (7) was implemented in IDL language. This function is composed by the sequence of autocorrelation coefficients $r_{k}$, until lag order $k$. For stationary processes, the ACF general equation is calculated from:

$\widehat{r}_{k}=\frac{\sum_{t=k+1}^{N}\left(y_{t}-\bar{y}\right) \cdot\left(y_{t-k}-\bar{y}\right)}{\sum_{t=1}^{N}\left(y_{t}-\bar{y}\right)^{2}}$

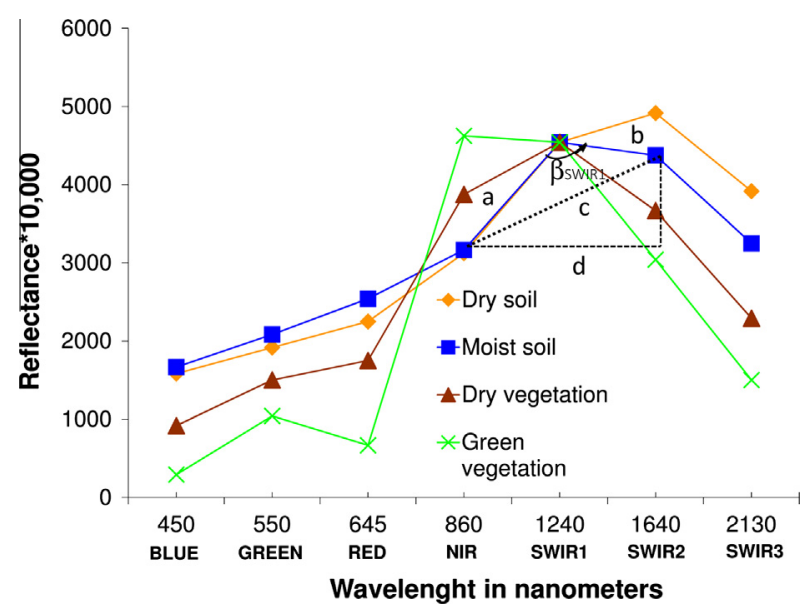

Fig. 3. Relationship between angle $\beta_{\text {SWIR } 1}$ formed at SWIR 1 and the slope of line $c$ Spectral values have been forced to coincide at SWIR1 to illustrate the relationship between angle and slope in SASI (adapted from Palacios-Orueta et al., 2006). a, b, c and $\mathrm{d}$ are referred to the Euclidean distances between the wavelength and reflectance at NIR (RNIR) and SWIR2 (RSWIR2). 
where $\widehat{r}$ is the autocorrelation coefficient for lag $k, y$ is the studied variable and $\bar{y}$ is the mean value of $y$.

The average ACF was calculated for each index to explore general rice crop dynamics. To assess the consistency of temporal patterns within each study area, spatial variability in index dynamics based on ACF values was evaluated by means of the Spectral Angle Mapper algorithm (SAM) (Kruse et al., 1993). The SAM is a tool that was originally implemented for mapping spectral similarity between image and reference spectra. In this model, a spectrum is considered a vector with a dimensionality equal to the number of bands. Thus, the difference in shape between the two spectra can be calculated as the "angular distance" between two vectors. In this work, the ACF was defined as an n-dimensional vector so that the difference in dynamics between two time series could be evaluated as the difference in shape between corresponding ACF values based on the angular distance between them. Therefore, small angle values indicate a high similarity in shape between ACFs and so, similar dynamics. This analysis was performed on a pixel scale so that the average ACF and angular distance between each pixel ACF could be calculated, and the pixels were classified into four categories, based on their similarities with average dynamics. A rice mask derived from digital crop maps was used in both zones. The results obtained were used to verify the soundness of using annual average index time series to represent general behaviors in each study site.

\subsubsection{Seasonal behavior of spectral indices in Orellana and the Ebro} Delta. Assessment of the performance in agro-practices and hydroperiod detection

The spatial average of the average year for the four indices was calculated in each area. The resulting values were used to explore general index patterns and to characterize significant points that coincided with agro-practices data. Variations in index behaviors during transition dates and their sensitivity to variations in soil humidity, flooding regimes and management practices were also assessed. In this study, results were expressed in terms of the MD (MODIS Date) in reference to each MODIS 8-day composite. For the average year, $46 \mathrm{MDs}$ determined from calculations on 552 images from the 2001-2012 MODIS dataset were analyzed.

The relationship between MD, crop and agro-practices dates is described in Table 2. The term DOY represents the range of days of the year corresponding with the phenological stage or a specific agricultural practice, and MDOY (MODIS Date Of the Year) represents the range of days closest to the agricultural stage during which a MODIS image was obtained.

Annual average indices were used to assess the spatial consistency of significant points and differences in behavior between indices depending on agricultural practices, phenological stages and flooding regimes in each zone. A specific combination of indices adapted to different management practices and flooding conditions was proposed for assessing hydroperiod, agricultural practices and stages for rice.

\subsubsection{Validation}

The absolute and relative maxima and minima dates provided in the annual profiles of the four indices (average 2001-2012) on a pixel basis were identified and compared with the dates of key agro-practices, rice cycle dynamics and flooding events. The coincidence between the derived phenometrics and agro-practices and crop stages in each study area was assessed based on the percentage of well-detected pixels for each index, phenometrics and region. To account for management variability, a margin of error of one week for $\mathrm{F}$ and HD and two weeks for $\mathrm{H}$ and EEF before and after the dates provided was permitted. Ground reference information consisted of a range of dates during which rice stages occurred and main agricultural practices were accomplished (Table 2). This information was provided by farmers and was used for validation purposes. Though data were not specific for each year and were instead based on general date ranges, phenometrics were identified for 12-year average indices. The distribution of the occurrence date (MD) of maxima and minima in the average annual profile for each index and region was explored using histograms. The length of the time series and high autocorrelation values at annual lags were used to corroborate the appropriateness of using the average year to represent the behavior of rice crop dynamics in each region.

A workflow diagram containing the main steps followed in the analysis performed is explained in Fig. 4.

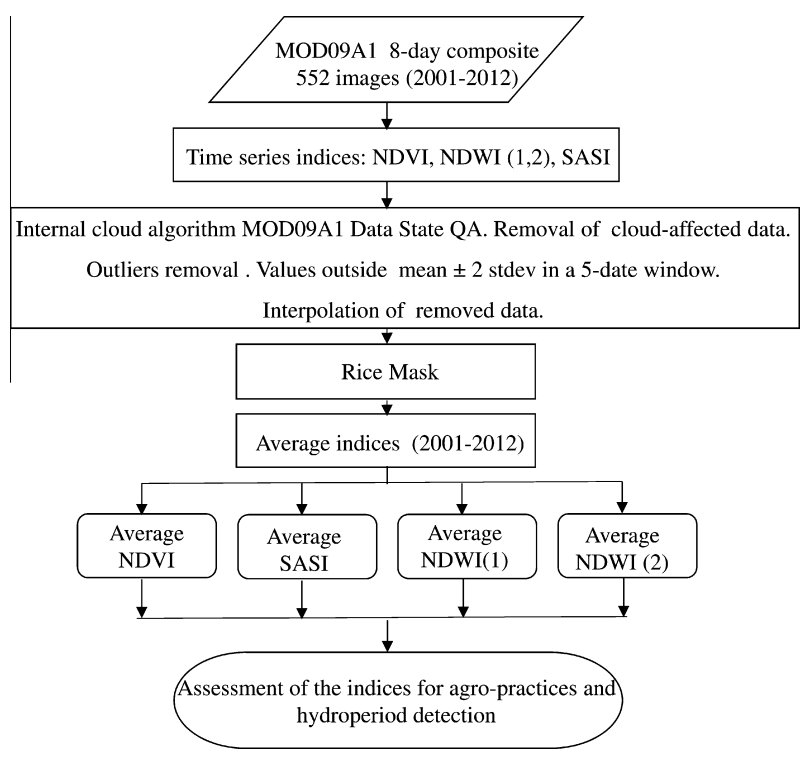

Fig. 4. Workflow diagram illustrating the main steps followed in this study. The image processing steps (first, second and third boxes) are described in Sections 4.1 and 4.2, and the rest of them in Section 4.2.

Table 2

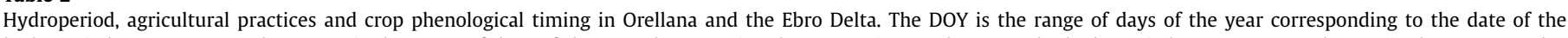

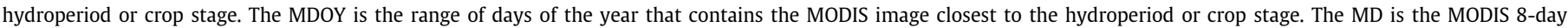
composite of the series of 46 annual images. (-) denotes an absence of a particular event in the zone studied.

\begin{tabular}{|c|c|c|c|c|c|c|c|c|}
\hline \multirow[t]{2}{*}{ Rice phases } & \multicolumn{4}{|l|}{ Ebro Delta } & \multicolumn{4}{|l|}{ Orellana } \\
\hline & Date & DOY & MDOY & MD & Date & DOY & MDOY & MD \\
\hline Flooding (F) & April 15th-May 1st & $105-121$ & $105-128$ & $14-16$ & April 25th-May 9th & $115-129$ & $113-136$ & $15-17$ \\
\hline Heading date (HD) & July 25th-30th & $206-211$ & $201-216$ & $26-27$ & July 25th-August 5th & $206-217$ & $201-216$ & $26-27$ \\
\hline Harvest $(\mathrm{H})$ & September 1st-30th & $244-273$ & $249-280$ & $32-35$ & September 30th-October 8th & $273-281$ & $273-288$ & $35-36$ \\
\hline End of the Env. Flooding (EEF) & January 15 th-February 15 th & $15-46$ & $17-48$ & $3-6$ & - & - & - & - \\
\hline
\end{tabular}




\section{Results}

\subsection{Time series analysis}

For each index considered, the autocorrelation function (ACF) was calculated to assess vegetation and water dynamics. Rice fields were classified into four categories based on similarities in dynamics (shape of the ACF) to the average ACF for each study area using the SAM algorithm. Figs. 5a, 6a, 7a and 8a show the average ACF values for each index and study area as well as the representative ACF for each category. Figs. 5b, 6b, $7 \mathrm{~b}$ and $8 \mathrm{~b}$ show the results of the SAM classification, which represents the spatial variability of different ACF types, and therefore the spatial variability of index dynamics.

NDVI ACF values presented significantly high positive values at 46 lags (one year) and significantly negative values at 23 lags (half a year) in the Delta (Fig. 5a), denoting a stable, single, cyclical pattern. The rest of the time series (Figs. 5a, 6a, 7a and 8a) showed significantly positive ACF values at one-year lag but did not present significantly negative ACF values at the half-year mark. Instead, ACF values were higher at 23 lags than at 12 and 36 lags, suggesting the presence of a secondary cycle during the year.

The NDVI and SASI time series presented high correlation values at one-year lag (Figs. 5a and 6a) while NDWI(1) showed intermediate ACF values, with the lowest values found in Orellana (Fig. 6a), which also showed the highest degree of spatial variability. The NDWI(2) values in the Ebro Delta exhibited correlation values at one-year lag in a similar manner as NDVI, whereas Orellana exhibited intermediate values (Fig. 7a).

Autocorrelation values at lag 23 presented larger differences between categories in each study area than those at the one-year lag. Relevant differences in NDVI and SASI ACF average patterns were located at the borders of the study sites in both zones (Figs. 5b and $8 \mathrm{~b}$ ) and were most likely caused by mixed pixels. This effect was also present and more noticeable in $\operatorname{NDWI}(1)$ and NDWI(2) (Figs. 6b and Fig. 7b). Regardless, pixels exhibiting this dynamic were few, relative to the rest of the pixels. NDWI(1) ACF values at 23 lags in Orellana were close to 0 and exhibited consid- (a)
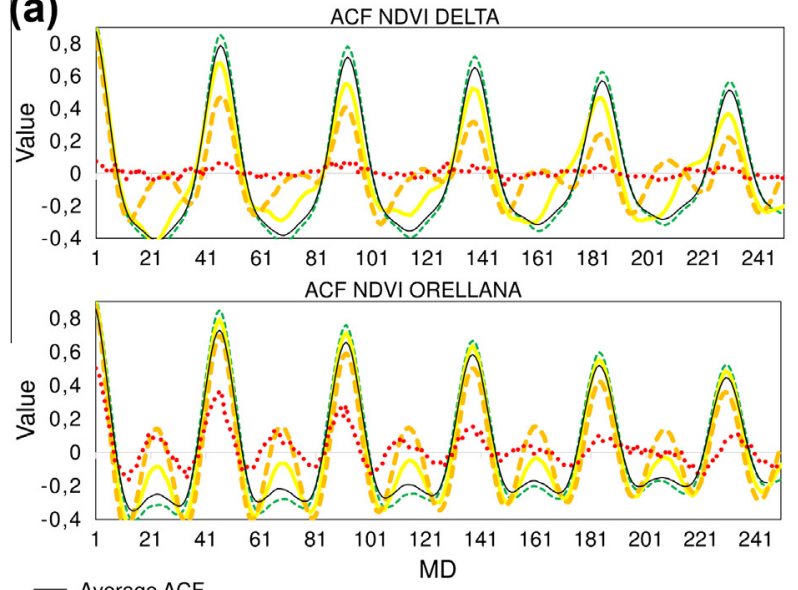

- Average ACF

- Very small deviation from the average $\quad \square$ Large deviation from the average ACF ACF

Small deviation from the average ACF .........Very large deviation from the average ACF
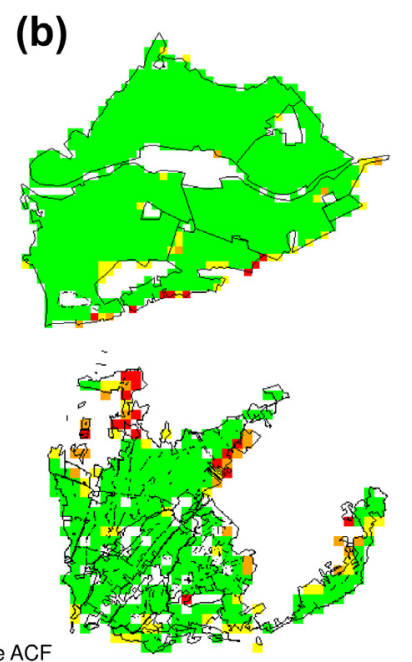

Fig. 5. Average NDVI ACF and variations of NDVI ACF (a) in the Ebro Delta (above) and Orellana (below). Spatial differences detected (b).

(a)
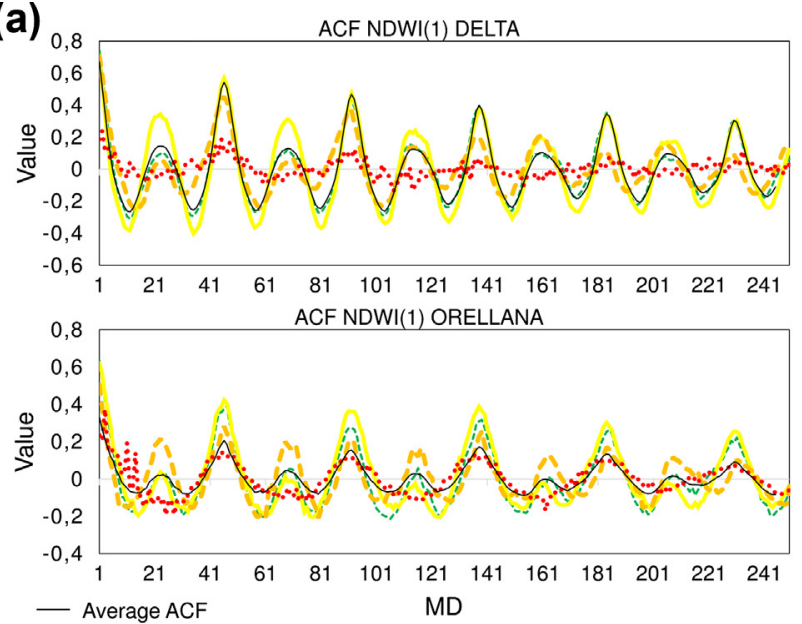

- Average ACF

Very small deviation from the average ACF

Small deviation from the average ACF Very large deviation from the average ACF (b)
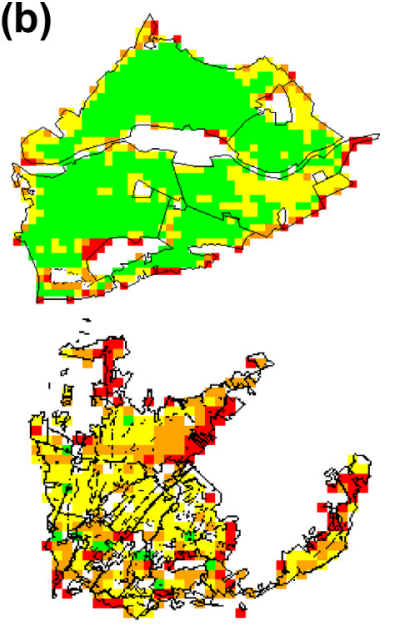

Fig. 6. Average NDWI(1) ACF and variations of NDWI(1) ACF (a) in the Ebro Delta (above) and Orellana (below). Spatial differences detected (b). 
erable spatial variability, although the spatial distribution presented consistent patterns (Fig. 6b). In the Delta, the NDWI(1) ACF showed spatially consistent positive values that were higher in the eastern region close to the river mouth and coastline. A similar spatial pattern was shown by $\operatorname{NDWI}(2)$ (Fig. 7b), which presented lower ACF values.

\subsection{Seasonal behavior of spectral indices}

The seasonal behavior of indices and the identification of key agricultural practices and phenological stages for each study area (Table 2) were determined based on the average year profile.

The average time series for both areas is shown in Fig. 9a-d to complement information showed in index annual profiles. Fig. 10a-d show the index annual profiles for Orellana and the Delta. General flooding and agricultural dates provided by farmers (Table 2), (i.e., flooding $(F)$, heading date (HD), harvest $(H)$ and the end of environmental flooding (EEF)) are also annotated.

The NDVI presented similar patterns during the growing season (Fig. 10a) in both areas, and differences were noticeable throughout the non-growing period (from the beginning of October to the beginning of May), with values in the Delta being consistently lower than those in Orellana. In both areas, minimum values occurred at the beginning of the flooding stage (April 15th-25th to May 1st-9th), while maximum values appeared close to the heading date.

The NDWI(1) and NDWI(2) profiles (Fig. 10b and c) showed two major local minima at the beginning and end of the rice flooding season (beginning of April and beginning of October). Both indices showed a sharp increase in coincidence with rice flooding in both areas (April 15th-25th) and at the beginning of environmental flooding in the Ebro Delta (first week of October). The opposite trend was observed after fields were drained before harvest in both areas (from roughly September 1 st to 30 th-October 8 th) and at the end of environmental flooding in the Delta (from January 15th to February 15th), with a relative minimum occurring at the end of the draining process.

The SASI (Fig. 10d) showed similar shape and value characteristics in both study areas during the growing period, and differences were noticeable in the Delta during the environmental flooding (a)
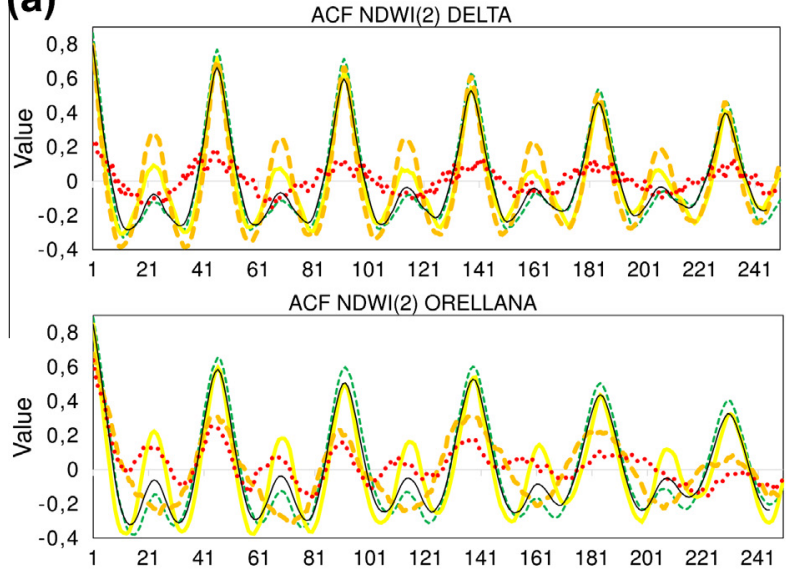

- Average ACF

Very small deviation from the average ACF

$\square$ Small deviation from the average ACF ....... Very large deviation from the average ACF (b)
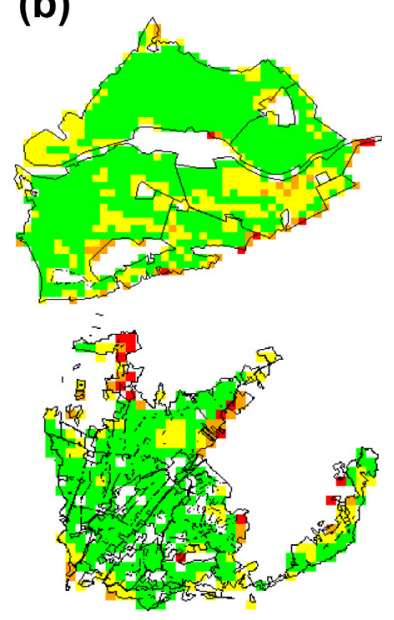

Fig. 7. Average NDWI(2) ACF and variations of $\operatorname{NDWI(2)~ACF~(a)~in~the~Ebro~Delta~(above)~and~Orellana~(below).~Spatial~differences~detected~(b).~}$

(a)
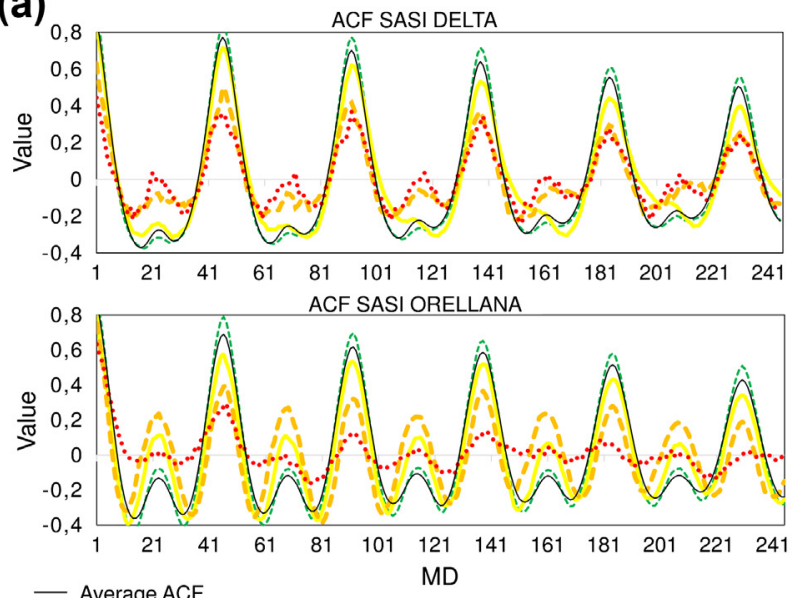

- Average ACF

Very small deviation from the average $\quad \square$ Large deviation from the average ACF

$\square$ Small deviation from the average ACF ........Very large deviation from the average ACF
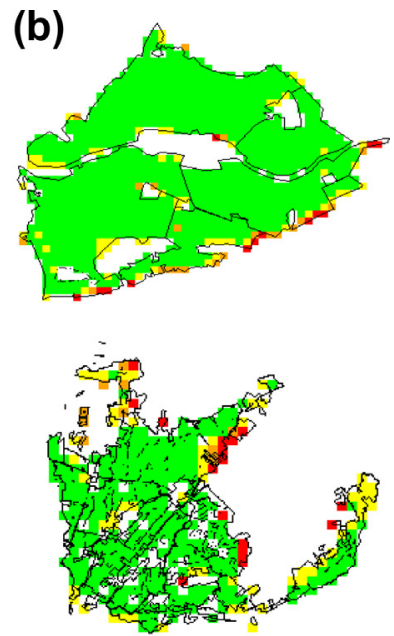

Fig. 8. Average SASI ACF and variations of SASI ACF (a) in the Ebro Delta (above) and Orellana (below). Spatial differences detected (b). 
stage (October 1st-January 15th). In both areas, an absolute maximum occurred at the beginning of the rice flooding stage (April 15th-25th). Minimum values in both sites at the end of July occurred close to the crop heading date, while a relative maximum occurred near the end of the harvest. This maximum was less noticeable in Orellana than in the Delta and appeared after a two-week delay according to field data. SASI trends also showed a relative minimum before the end of the environmental flooding period.

Table 3 shows identified singular points that may be related to specific dates of agricultural practices provided by farmers.
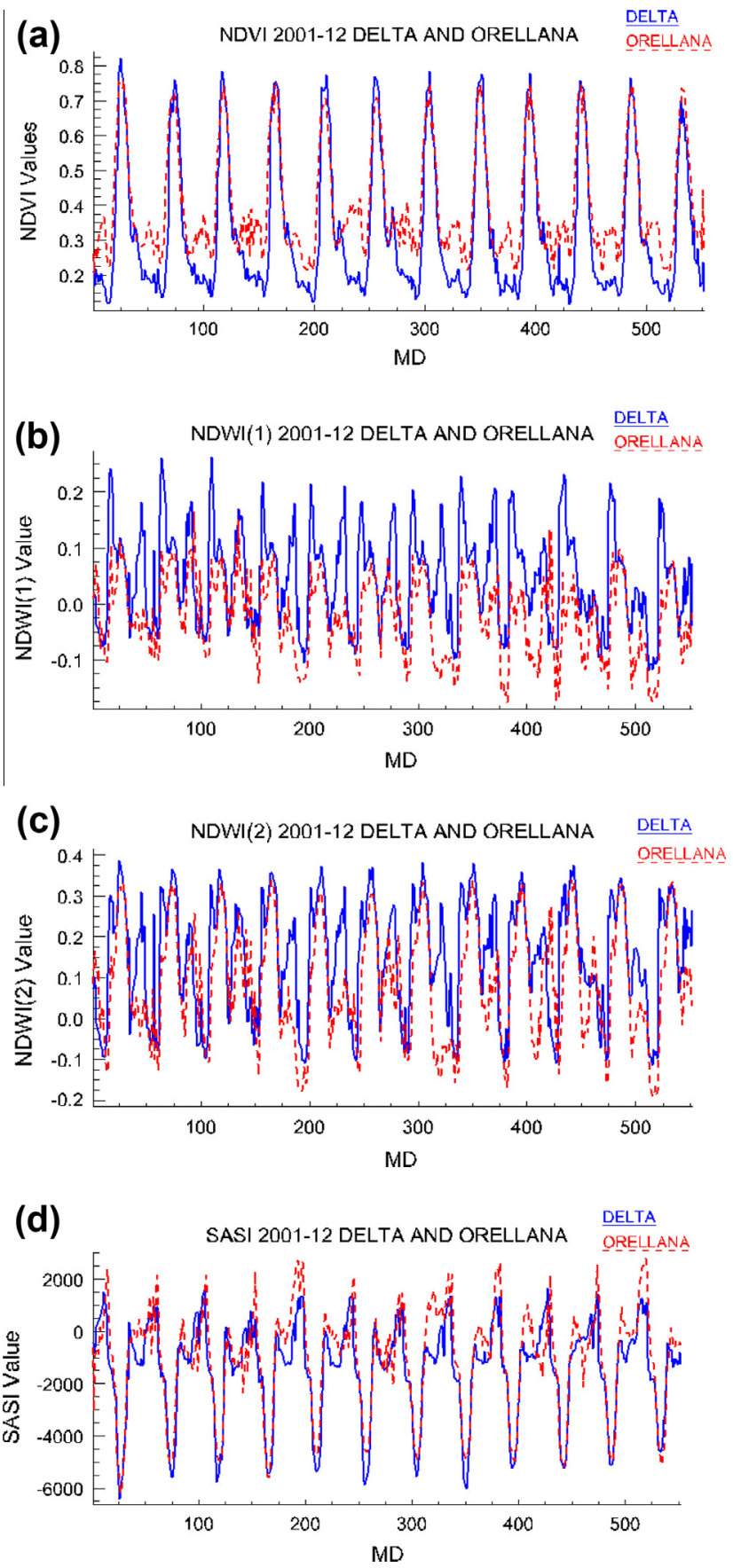

Fig. 9. Average NDVI (a), NDWI(1) (b), NDWI(2) (c) and SASI (d) time series (20012012) for the Ebro Delta and Orellana.

\subsection{Assessment of agricultural practices and hydroperiod detection} performance

Key singular points identified on the average annual profiles (Table 3) were also determined on a pixel scale for the average year in both study areas and then compared with dates provided by local farmers. Table 4 shows the percentage of pixels in which a singular point was detected within the range of occurrence dates for each stage based on a margin of error as described in point 2.3.

Figs. 11-14 show histograms for these singular points; only those that could be related to a specific rice or flooding stage are represented. Values are presented as a percentage of the total number of pixels in each study area.

Approximately $84 \%$ and $85 \%$ of the Delta and Orellana NDVI profiles, respectively, exhibited a minimum within the range of flooding occurrence dates (Table 4). Ninety percent of the Orellana SASI pixels reached a maximum during this period of the year with a narrow distribution (Fig. 11b). However, coincidence was much lower in the Delta.

Maximum values detected in NDVI within the range of dates defined for the heading date were close to $97 \%$ and $90 \%$ in the Delta and Orellana, respectively (Table 4). The SASI showed a minimum of $94 \%$ of pixels in the Delta for this period while in Orellana this ratio dropped to $83 \%$. Although in both indices the histograms of the maximum point in SASI were narrow, in Orellana the maximum appeared after an 8-day delay relative to NDVI data (Fig. 12b).

Minimum values in $\operatorname{NDWI}(2)$ and $\operatorname{NDWI}(1)$ that were concurrent with the harvest period were detected in $93 \%$ and $91 \%$ of the pixels for the Delta (Table 4), while in Orellana this coincidence was observed in only $39 \%$ and $54 \%$ of the pixels. Over this range of dates, the SASI index showed a maximum in $90 \%$ and $60 \%$ of the pixels in the Delta and Orellana, respectively. In the Delta, $\operatorname{NDWI}(1), \operatorname{NDWI}(2)$ and SASI singular points were located within a narrow interval of dates (Fig. 13a), whereas points in Orellana were more broadly distributed. Additionally, the minimum value in $\operatorname{NDWI}(2)$ was delayed by two weeks relative to points detected by NDWI(1) and SASI (Fig. 13b).

The NDWI(1) and SASI presented minimum values in $80 \%$ and $69 \%$ of the pixels within the range of dates defined as the end of the environmental flooding period in the Delta (Table 4). The histograms showed that the majority of points were situated within a three-week interval in both indices (Fig. 14); however, the SASI minimum values appeared three weeks before those of NDWI(1), and a notable number of pixels presented a six-week delay relative to the main group.

Fig. 15a-d show the combination of indices that achieved the best results for the Delta and Orellana according to field data (also annotated) for a single pixel (Fig. 15a and b) and for the average year (Fig. 15c and d).

\section{Discussion}

In this study, the behaviors of four MODIS indices for assessing the agricultural practices (flooding and harvesting period), rice heading stage occurrence and hydroperiod characteristics in rice were analyzed in the study areas. The effectiveness of these indices in assessing soil surface statuses during transition periods in relation to the flooding regime was of special interest. The results obtained through the exploration of the ACF and its annual dynamics proved the soundness of evaluating agricultural practices and rice crop dynamics based on the analysis of spectral indices for a reference year, computed as the multi-year average for the studied period. The occurrence of two intra-annual cycles in the ACF of some indices denoted the existence of two maxima or two minima 

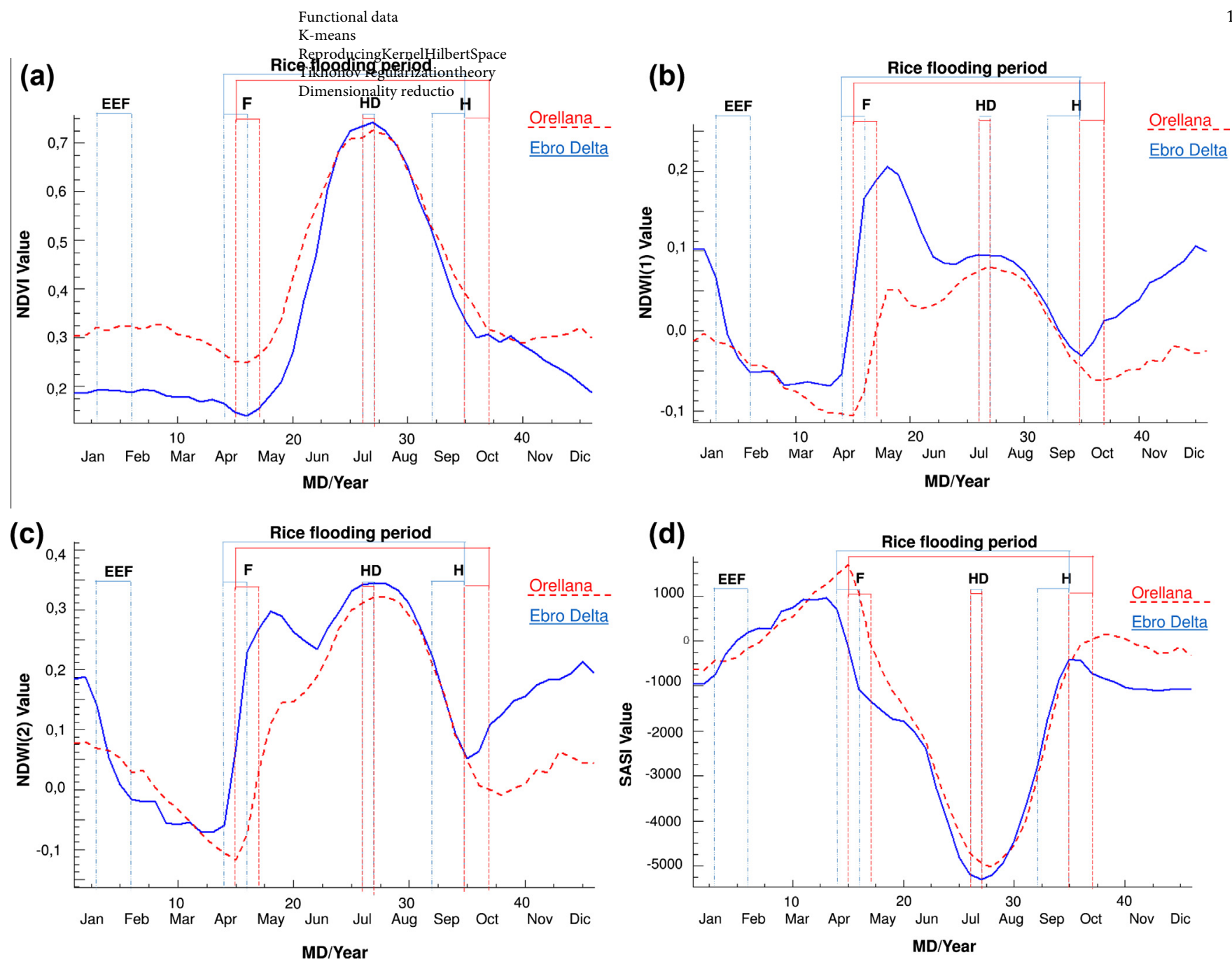

Fig. 10. Average annual profile of NDVI (a), NDWI(1) (b), NDWI(2) (c) and SASI (d) (2001-2012) for the Ebro Delta and Orellana.

per year. Thus, the methodology for assessing index performance was based on the detection of minimum and maximum points as phenometrics of average indices for the period (2001-2012). The points identified were compared with average dates of agricultural practices provided by local farmers to test the consistency between indices and field data. The detection of phenometrics worked more effectively overall for the Delta than for Orellana, most likely due to the homogeneity of the Delta, both with respect to land cover and to agricultural management practices.

The NDVI ACF presented the highest values at one-year lag, illustrating the consistency of annual patterns throughout the 2001-2012 period (Fig. 5a). Spatial variability was found to be low, demonstrating the representativeness of the average profile for identifying phenometrics. The NDVI ACF of the Delta was the only one denoting a single intra-annual cycle (Fig. 5a), with negative AC values at a 23 lag (half a year). This behavior indicated that NDVI distinguished active crop stages from non-photosynthetic stages, though it did not capture variability during the non-growing season (i.e., bare soil vs. environmental flooding). In contrast, the NDVI ACF revealed a double intra-annual cycle in Orellana (Fig. 5a), suggesting variability during the non-growing period, which may be attributed to the presence of weeds in the fields.

The NDVI average profile presented a maximum close to the heading date (Fig. 10a) and coincident with the maximum LAI (Boschetti et al., 2009; Wang et al., 2012). The lack of noise in this index and the consistency of the maximum resulted in high levels of agreement with field data (Table 4). Low autumn-winter NDVI values in the Delta occurred due to the combined effect of vegetation residue and flooded soils, and these values decreased slightly after the fields were drained. After this, the index reached a distinct local minimum prior to crop emergence that matched the subsequent flooding stage (Fig. 10a). The occurrence of this minimum within the range of dates provided was observed in $84 \%$ of the pixels (Table 4), accurately denoting a transition from bare flooded soil to rice emergence. This minimum was also present in Orellana (Fig. 10a), where similar results were achieved (Table 4). For this area, the existence of a SASI maximum that coincided with the start of the hydroperiod (Fig. 10d) was more accurately detected (Fig. 11b). The consistency of this maximum is most likely attributed to the response of this index to dryness in bare soils prior to flooding. SASI was expected to reach higher values for bare, dry soil stages and lower values for wet and flooded soils (Khanna et al., 2007). In fact, other studies have proposed the use of threshold values in SASI to track soil wetness (Das et al., 2013). High SASI ACF values and the existence of a distinct, biannual pattern in Orellana (Fig. 8.a) were in agreement with the presence of this maximum. In the Delta, on the other hand, soils were not completely dry by the beginning of the hydroperiod due to environmental flooding. This reduced the contrast between soils before and after flooding, resulting in a less significant SASI maximum (Fig. 10d). Differences in soil moisture dynamics between the study areas were most likely the cause of the different results in the detection of the flooding period by SASI. 
The performance of indices in identifying the harvest showed consistently better results in the Delta than in Orellana (Table 4). This is likely attributable to differences in management practices between the two areas. In the Delta, the harvest process resulted in a transition from wilting vegetation to flooded soils that produced a more distinct minimum in $\operatorname{NDWI}(1)$ and $\operatorname{NDWI}(2)$ and a maximum in SASI (Fig. 10b-d). In Orellana, the transition from wilting vegetation to bare dry soil was not as easily identifiable, especially in $\mathrm{NDWI}(2)$ (Fig. 13b). In this area, the SASI relative maximum was correctly identified in a higher percentage of pixels than the minima in $\operatorname{NDWI}(1)$ and $\operatorname{NDWI}(2)$ (Table 4). These findings complement the results of other researchers who found that SASI effectively identifies wilting vegetation in both wet and dry soil (Khanna et al., 2007). The existence and consistency of these points in $\operatorname{NDWI}(1), \operatorname{NDWI}(2)$ and SASI was in agreement with the double ACF pattern identified (Figs. 6a, 7a, 8a), denoting the occurrence of distinct dynamics throughout the non-growing season.

During environmental flooding, both $\operatorname{NDWI}(2)$ and $\operatorname{NDWI}(1)$ exhibited higher values in the Delta than in Orellana (Fig. 10b and c) due to the presence of water in the fields. The SASI index also detected these differences in water management, showing consistently lower values in the Delta (Fig. 10d). Khanna et al (2007) showed that SASI detects higher values in dry soils, and this is in agreement with the results obtained. This finding highlights the importance of SWIR bands for rice monitoring during the non-photosynthetic period.

Both SASI and NDWI(1) provided relevant information on the beginning and end of the drying process following the hydroperiod in the Delta. In $69 \%$ of the pixels, SASI presented a minimum in coincidence with the beginning of the drainage process (Fig. 10d), illustrating an increasing trend as water levels decreased. On the other hand, NDWI(1) showed a minimum value at the end of the field drainage period (Fig. 10b). After this point, the index recorded stable values. This finding is consistent with other works that discuss the response of this index to soil and vegetation water content (Gao, 1996). The secondary cycle at lag 23 in the NDWI(1) ACF (Fig. 6) is most likely attributable to its regular response to environmental flooding, allowing for highly accurate means of identifying this stage (Table 4). The combination of results obtained from the two indices may provide an estimation of field drainage period length at the end of the hydroperiod in the Delta (Fig. 14), improving the robustness of its characterization.

Table 3

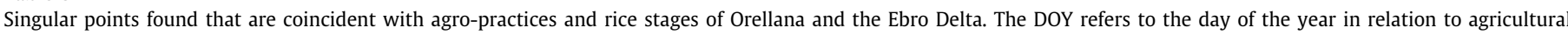
practices and crop stages.

\begin{tabular}{|c|c|c|c|c|c|c|c|}
\hline & \multicolumn{2}{|l|}{ Flooding $(\mathrm{F})$} & \multicolumn{2}{|c|}{ Heading date (HD) } & \multicolumn{2}{|l|}{ Harvesting $(\mathrm{H})$} & \multirow{2}{*}{$\begin{array}{l}\text { End Env. Flooding (EEF) } \\
\text { Delta }\end{array}$} \\
\hline & Delta & Orellana & Delta & Orellana & Delta & Orellana & \\
\hline NDVI & $\begin{array}{l}\text { Abs. minimum } \\
\text { DOY: } 121-128\end{array}$ & DOY: $121-128$ & $\begin{array}{l}\text { Abs. maximum } \\
\text { DOY: } 209-216\end{array}$ & DOY: 209-216 & & & \\
\hline $\operatorname{NDWI}(1)$ & $\begin{array}{l}\text { Rel. maximum } \\
\text { DOY: } 137-144\end{array}$ & DOY: $145-152$ & & & $\begin{array}{l}\text { Rel. minimum } \\
\text { DOY: } 273-280\end{array}$ & DOY: $281-288$ & $\begin{array}{l}\text { Rel. minimum } \\
\text { DOY: } 41-49\end{array}$ \\
\hline $\operatorname{NDWI}(2)$ & & & $\begin{array}{l}\text { Abs. maximum } \\
\text { DOY: 209-216 }\end{array}$ & DOY: 209-216 & $\begin{array}{l}\text { Rel. minimum } \\
\text { DOY: } 273-280\end{array}$ & DOY: 297-304 & \\
\hline SASI & $\begin{array}{l}\text { Abs. maximum } \\
\text { DOY: 97-104 }\end{array}$ & DOY: $113-120$ & $\begin{array}{l}\text { Abs. minimum } \\
\text { DOY: 209-216 }\end{array}$ & DOY: $217-224$ & $\begin{array}{l}\text { Rel. maximum } \\
\text { DOY: } 273-280\end{array}$ & DOY: 297-304 & $\begin{array}{l}\text { Rel. minimum } \\
\text { DOY: 9-16 }\end{array}$ \\
\hline
\end{tabular}

Table 4

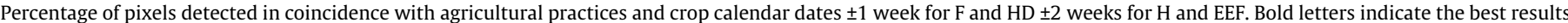
achieved. (-) Indicates non-assessed indices; (B) refers to the start of field drainage, and (E) refers to the end of the drainage process.

\begin{tabular}{|c|c|c|c|c|c|c|c|c|}
\hline & \multicolumn{2}{|c|}{ Flooding $(\mathrm{F})$} & \multicolumn{2}{|c|}{ Heading date (HD) } & \multicolumn{2}{|c|}{ Harvesting $(\mathrm{H})$} & \multicolumn{2}{|c|}{ End Env. Flooding (EEF) } \\
\hline & Delta & Orellana & Delta & Orellana & Delta & Orellana & Delta (B) & Delta (E) \\
\hline NDVI & 83.8 & 85.3 & 96.8 & 90.4 & - & - & - & - \\
\hline $\operatorname{NDWI}(1)$ & 23.9 & 14.4 & - & - & 91.0 & 51.4 & & 80.0 \\
\hline $\operatorname{NDWI}(2)$ & - & - & 83.8 & 76.6 & 93.3 & 39.0 & - & - \\
\hline SASI & 38.1 & 89.8 & 93.6 & 83.1 & 90.3 & 60.5 & 69.0 & - \\
\hline
\end{tabular}
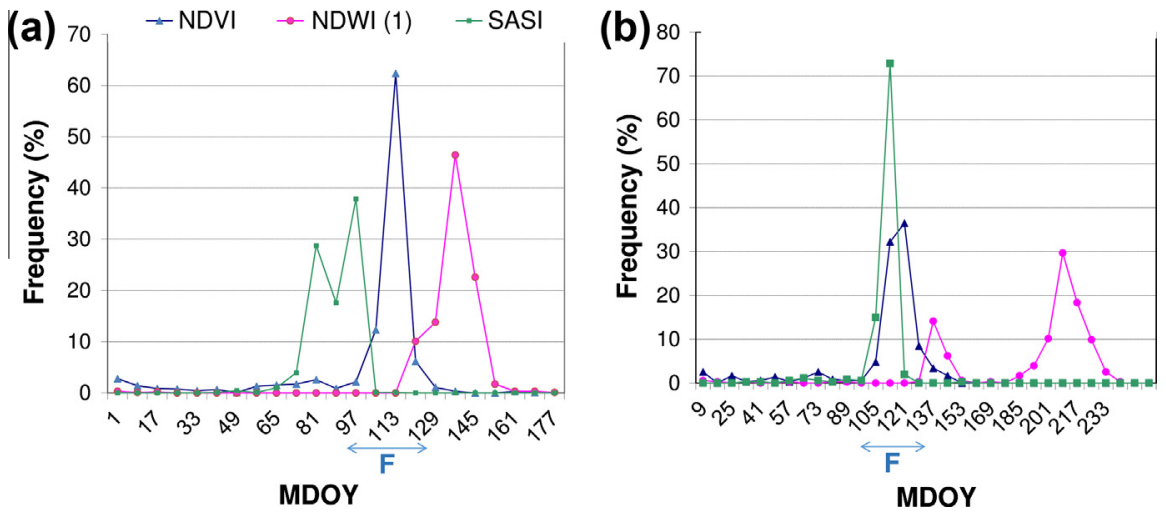

Fig. 11. Frequency distribution of singular points for NDVI, SASI and NDWI(1) close to F in the Ebro Delta (a) and Orellana (b) on a per-pixel basis. 

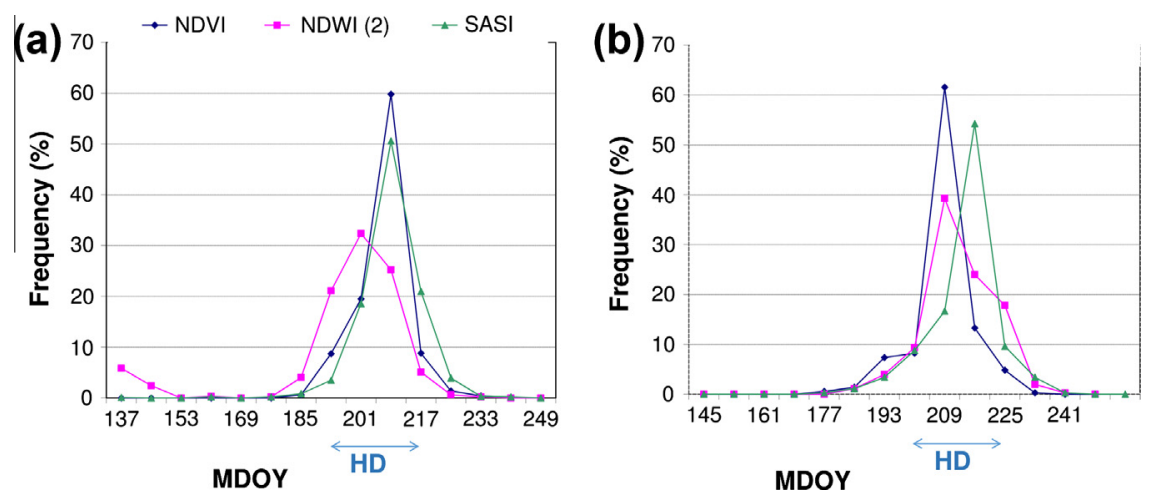

Fig. 12. Frequency distribution of singular points in NDVI, SASI and NDWI(2) close to HD in the Ebro Delta (a) and Orellana (b) on a per-pixel basis.
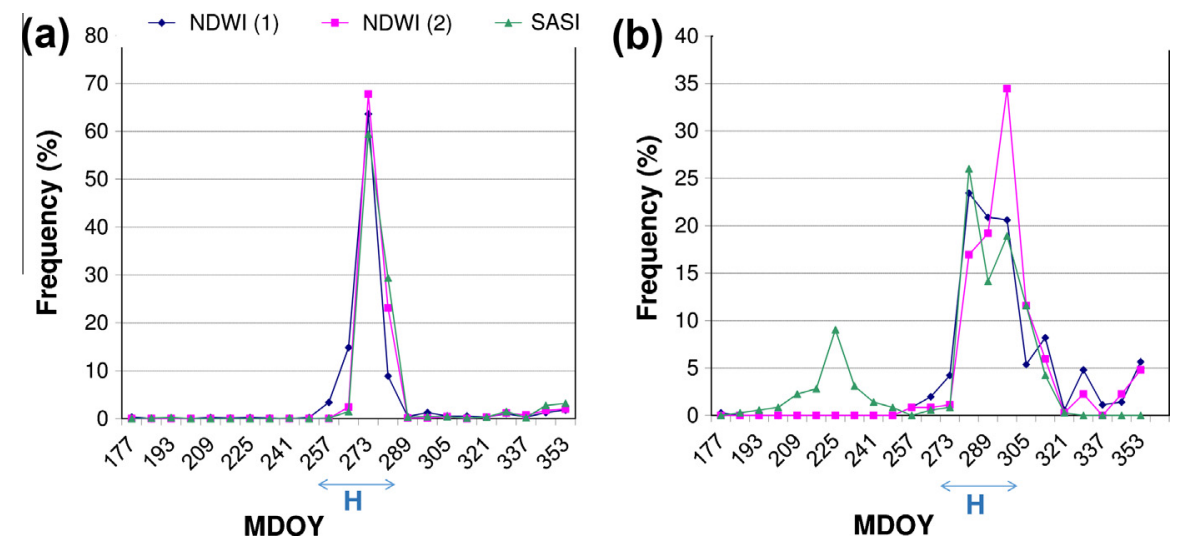

Fig. 13. Frequency distribution of singular points in $\operatorname{NDWI(1),~NDWI(2)~and~SASI~close~to~H~in~the~Ebro~Delta~(a)~and~Orellana~(b)~on~a~per-pixel~basis.~}$

Our results showed that the dates of agricultural practices, heading stages and hydroperiod in rice may be identified by combining information derived from the four indices studied. Index behaviors in rice paddies in which soils were dry from harvesting until the following rice season (i.e., Orellana) differed from those in rice paddies in which flooding occurred after harvesting (i.e., Delta). In addition, each index exhibited different capabilities during different periods of the year. These results suggest that it is appropriate to use different combinations of indices to detect hydroperiod and agricultural practices in regions with different soil moisture dynamics throughout the year (Fig. 16).

The NDVI relative minimum may be used to detect flooding stages in sites that are flooded or in which soils are kept moist

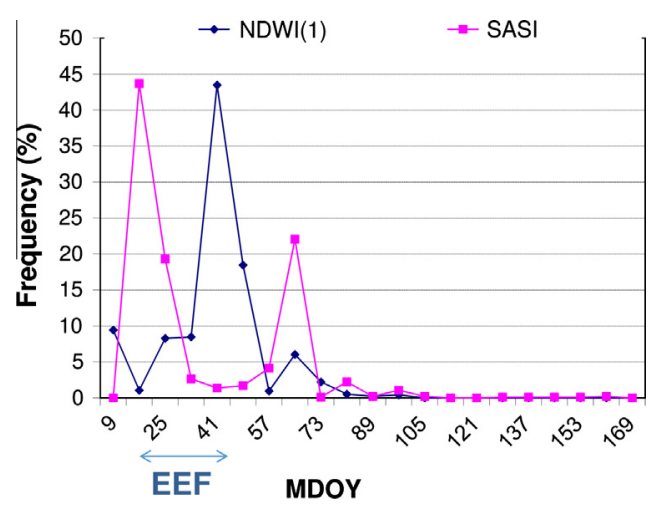

Fig. 14. Frequency distribution of singular points in SASI and NDWI(1) close to EEF in the Ebro Delta on a per-pixel basis. for the majority of the year. On the other hand, the SASI maximum would better suit fields with shorter hydroperiods and dry soils before the flooding stage. The maximum of NDVI could be used to detect heading date in any instance, and the minimum of SASI is the second best measure for this purpose. The relative minimum of $\operatorname{NDWI}(2)$ may be applied to detect harvesting in sites that include a second flooding event after harvesting, while the SASI maximum shows stronger results for transitions between vegetation wilting and soil drying than the rest of the indices. The minimum of SASI may be used to detect the start of the drainage process at the end of the environmental flooding period, and the $\operatorname{NDWI}(1)$ minimum can be applied to detect the end of the drainage process.

Though in this study rice fields were identified using a rice mask, other methodologies may be used to determine rice areas. Since rice fields are not typically managed under crop rotation schemes, once the rice fields are identified the proposed strategy could be used in a robust manner for areas under similar management practices. Our results, which showed significant stability in rice fields in the two study areas throughout the study period, support this hypothesis. Thus, a method for confirming crop permanence every year may be more appropriate than a mapping procedure. In this sense, the autocorrelation approach by means of the ACF provides essential information on the recurrence of similar patterns each year.

Fig. 16a and b show two schematic diagrams of the specific agricultural practices, crop stages and hydroperiod characteristics that could be identified by each of the indices tested in rice systems similar to Orellana and the Delta respectively. A specific combination of an index and a metric could be used to detect each stage. 
(a)

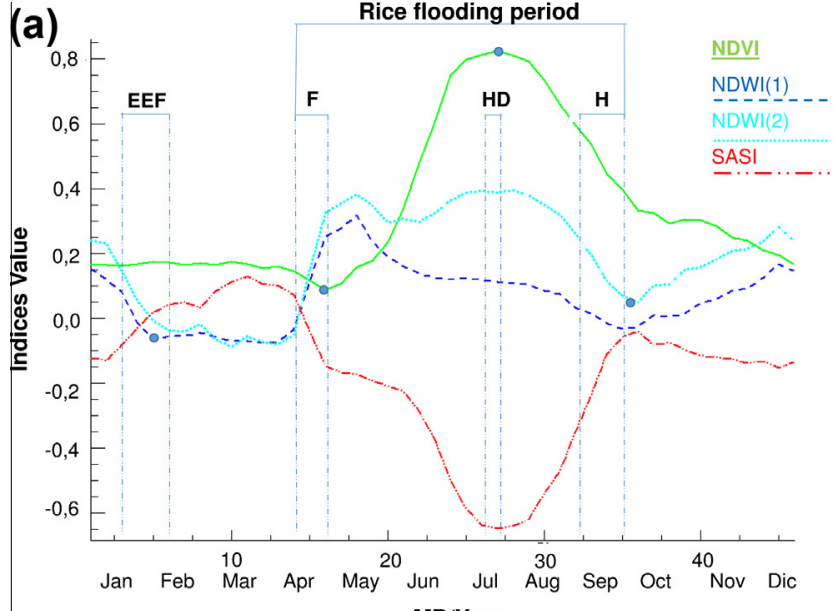

MD/Year

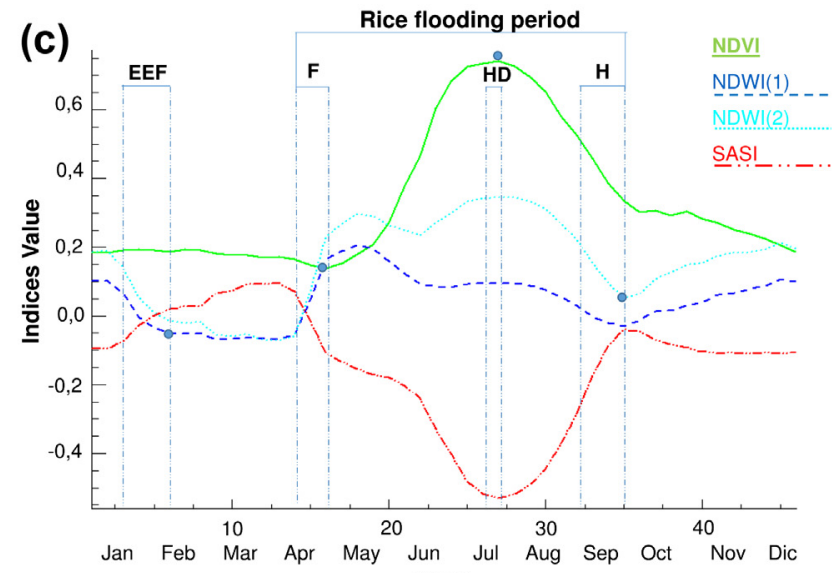

MD/Year

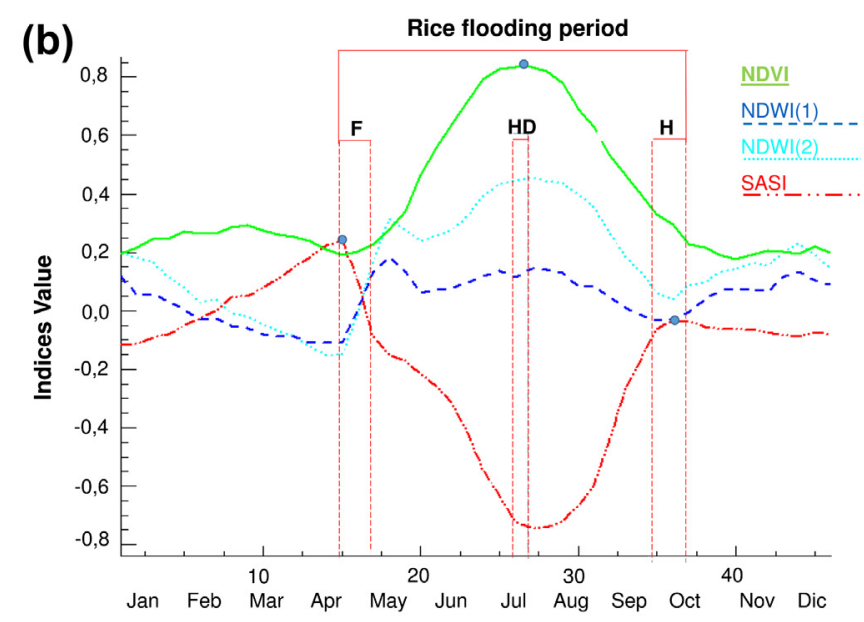

MD/Year

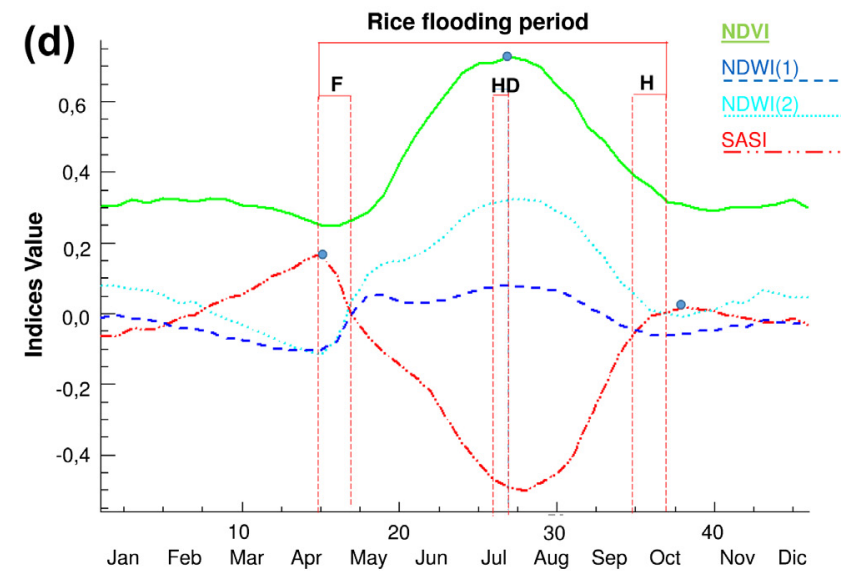

MD/Year

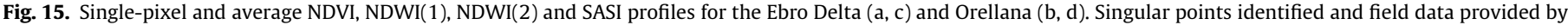
local farmers are also annotated.

(a)
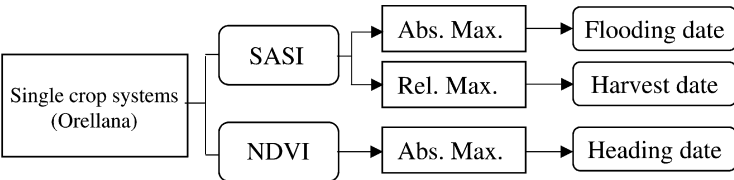

(b)

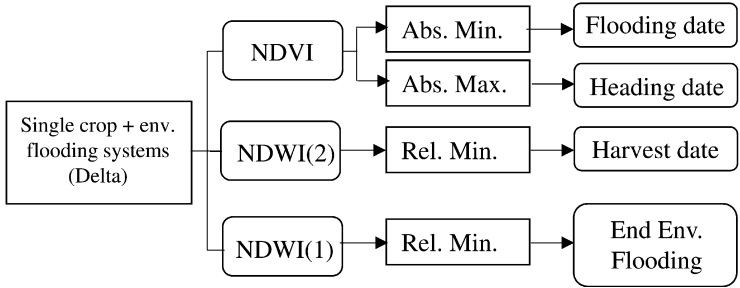

Fig. 16. Schematic diagram depicting the specific agricultural practices, crop stages and hydroperiod characteristics that could be identified by each index in rice systems similar to Orellana (a) and the Delta (b).

This work presented the results of the characterization and assessment of different indices behavior and dynamics in rice systems. The spatial and temporal stability shown within each area made it possible to evaluate the capability of the indices analyzed based on the average year; however, to develop an agro-monitoring tool, assessments should be applied to each specific year. In such cases, smoothing and validation procedures would be necessary.

\section{Conclusions}

In this study, indices exhibiting variable detection capacities depending on flooding regimes and management practices in different zones were identified. NDVI, NDWI(1) and NDWI(2) most effectively identified agricultural practices and hydroperiod characteristics in the Delta while NDVI and SASI performed better when applied to Orellana due to differences in soil moisture dynamics. Based on the results obtained, we have proposed a specific combination of indices for assessing rice flooding events, some crop stages and agricultural practices (Fig. 16) in relation to different management practices.

The main findings of this work are:

- Although NDVI effectively identified rice dynamics over the growing period, it was not able to assess the variability out of the growing season, which were more accurately assessed by $\operatorname{NDWI}(1), \operatorname{NDWI}(2)$ and SASI.

- The existence of a significant response to flooding events shown in $\operatorname{NDWI}(1), \operatorname{NDWI}(2)$ and SASI illustrates the importance of SWIR spectral wavelengths to detect flooded and wet soils. Specifically, SASI exhibited a strong capacity to identify changes in soil water content, and especially at the beginning of the drainage period, which may encourage its use in wetland monitoring studies. 
- A considerable consistency between the time series statistical analysis (i.e. ACF) and phenometrics approaches was shown by the coincidence between distinct phenometrics and the double cycle pattern of the ACF. The ACF provided useful information for assessing spectral indices dynamics and patterns related to vegetation and flooding dynamics in rice. The analysis performed identified the homogeneity in the pattern of the indices between years for the time series and the differences in the annual cycles due to changes in vegetation and flooding dynamics.

The generalization of these results to other rice regions will depend on specific water management practices in each area. The proposed combination for the Ebro Delta may most likely be applied to areas characterized by a double rice cycle, which may present similar transitional characteristics across agricultural events of dry soil, wet soil, green vegetation and wilting vegetation. The combination of indices that works more effectively in Orellana may be used in areas characterized by a single rice cycle, in which soil remains dry until the next rice season. The application of this approach as a monitoring tool should rely on the use of complete time series and specific validation.

This approach may improve rice phenometrics detection practices in many countries where crop calendars and water management monitoring resources are not accessible. The results obtained may be used to establish water management policies and for developing methane emissions and vegetation dynamics studies. The results showed that while rice crops exhibit a number of common patterns, management practices can differ, resulting in different dynamics that necessitate different approaches to rice crop monitoring from Remote Sensing.

\section{Acknowledgements}

This project was supported by the Centre for Hydrographic Studies (CEH-CEDEX) and by the project AGL-2010-17505 funded by the Spanish Ministry of Economy. We express our sincere thanks to the water user associations in the Ebro Delta and Orellana for their careful explanation of rice paddies management practices and the field data provided. We are also thankful to Confederación Hidrográfica del Guadiana (Ministry of Agriculture), for their help and the data provided regarding Orellana irrigation district.

\section{References}

Báez-González, A.D., Chen, P.Y., Tiscareño-López, M., Srinivasan, R., 2002. Using satellite and field data with crop growth modeling to monitor and estimate corn yield in Mexico. Crop Sci. 42 (6), 1943-1949.

Bauman, B., Kropff, M., Tuong, T., Wopereis, M., Berge, H., Laar, H., 2001 ORYZA2000: Modelling Lowland Rice. IRRI, Manila, Philippines.

Boschetti, M., Stroppiana, D., Brivio, P.A., Bocchi, S., 2009. Multi-year monitoring of rice crop phenology through time series analysis of MODIS images. Int. J. Remote Sens. 30 (18), 4643-4662.

Boschetti, M., Nutini, F., Manfron, G., Brivio, P.A., Nelson, A., 2014. Comparative analysis of normalised difference spectral indices derived from MODIS for detecting surface water in flooded rice cropping systems. PLoS ONE 9 (2), e88741.

Box, G., Jenkins, G., Reinsel, G., 1994. Time Series Analysis: Forecasting and Control, third ed. Prentice-Hall, Englewood Cliffs, New Jersey.

Chen, J., Jönsson, P., Tamura, M., Gu, Z., Matsushita, B., Eklundh, L., 2004. A simple method for reconstructing a high-quality NDVI time-series data set based on the Savitzky-Golay filter. Remote Sens. Environ. 91 (3), 332-344.

Chumkesornkulkit, K., Kasetkasem, T., Rakwatin, P., Eiumnoh, A., Kumazawa, I. Buddhaboon, C., 2013. Estimated rice cultivation date using an extended Kalman filter on MODIS NDVI time-series data. In: International Conference on Electrical Engineering/Electronics, Computer, Telecommunications and Information Technology (ECTI-CON), 2013 10th, pp. 1-6.

Das, P.K., Murthy, S.C., Seshasai, M.V.R., 2013. Early-season agricultural drought: detection, assessment and monitoring using Shortwave Angle and Slope Index (SASI) data. Environ. Monit. Assessment. 185, 9889-9902.
Delbart, N., Kergoat, L., Le Toan, T., Lhermitte, J., Picard, G., 2005. Determination of phenological dates in boreal regions using normalized difference water index. Remote Sens. Environ. 97 (1), 26-38.

Dingkuhn, M., Le Gal, P.Y., 1996. Effect of drainage date on yield and dry matter partitioning in irrigated rice. Field Crops Res. 46 (1), 117-126.

Dornelas, M., Magurran, A.E., Buckland, S.T., Chao, A., Chazdon, R.L., Colwell, R.K., Vellend, M., 2013. Quantifying temporal change in biodiversity: challenges and opportunities. Proc. Royal Society B: Biol. Sci. 280 (1750), 20121931.

Fang, H., Wu, B., Liu, H., Huang, X., 1998. Using NOAA AVHRR and Landsat TM to estimate rice area year-by-year. Int. J. Remote Sens. 19 (3), 521-525.

FAO, 2002. FAO Rice information. In: Nguyen, V.N., Labrada, R., Tran D.V. (Eds.), Food Agriculture Organization of the United Nations, vol. 3, Rome, Italy.

FAO, 2013. Rice in FAO. <http://www.fao.org/agriculture/crops/themes-principaux/ theme/treaties/irc/rice-in-fao/fr/> (accessed on 25.08.13).

Fensholt, R., Sandholt, I., 2003. Derivation of a shortwave infrared water stress index from MODIS near-and shortwave infrared data in a semiarid environment. Remote Sens. Environ. 87 (1), 111-121.

Gao, B.C., 1996. NDWI-a normalized difference water index for remote sensing of vegetation liquid water from space. Remote Sens. Environ. 58 (3), 257-266.

Gumma, M.K., Thenkabail, P.S., Maunahan, A., Islam, S., Nelson, A., 2014. Mapping seasonal rice cropland extent and area in the high cropping intensity environment of Bangladesh using MODIS $500 \mathrm{~m}$ data for the year 2010. ISPRS J. Photogramm. Remote Sens. 91, 98-113.

Huete, A., Didan, K., Miura, T., Rodriguez, E.P., Gao, X., Ferreira, L.G., 2002. Overview of the radiometric and biophysical performance of the MODIS vegetation indices. Remote Sens. Environ. 83 (1), 195-213.

Jacquin, A., Sheeren, D., Lacombe, J.P., 2010. Vegetation cover degradation assessment in Madagascar savanna based on trend analysis of MODIS NDVI time series. Int. J. Appl. Earth Obs. Geoinf. 12, S3-S10.

Kamthonkiat, D., Honda, K., Turral, H., Tripathi, N.K., Wuwongse, V., 2005. Discrimination of irrigated and rainfed rice in a tropical agricultural system using SPOT VEGETATION NDVI and rainfall data. Int. J. Remote Sens. 26 (12), 2527-2547.

Kerr, J.T., Ostrovsky, M., 2003. From space to species: ecological applications for remote sensing. Trends Ecol. Evol. 18 (6), 299-305.

Khanna, S., Palacios-Orueta, A., Whiting, M.L., Ustin, S.L., Riaño, D., Litago, J., 2007. Development of angle indexes for soil moisture estimation, dry matter detection and land-cover discrimination. Remote Sens. Environ. 109, 154-165.

Kimball, J.S., McDonald, K.C., Running, S.W., Frolking, S.E., 2004. Satellite radar remote sensing of seasonal growing seasons for boreal and subalpine evergreen forests. Remote Sens. Environ. 90 (2), 243-258.

Kruse, F.A., Lefkoff, A.B., Boardman, J.W., Heidebrecht, K.B., Shapiro, A.T., Barloon, P.J., Goetz, A.F.H., 1993. The spectral image processing system (SIPS)interactive visualization and analysis of imaging spectrometer data. Remote Sens. Environ. 44 (2), 145-163.

Leinenkugel, P., Kuenzer, C., Oppelt, N., Dech, S., 2013. Characterisation of land surface phenology and land cover based on moderate resolution satellite data in cloud prone areas-A novel product for the Mekong Basin. Remote Sens. Environ. 136, 180-198.

Li, P., Feng, Z., Jiang, L., Liu, Y., Xiao, X., 2012. Changes in rice cropping systems in the Poyang Lake Region, China during 2004-2010. J. Geogr. Sci. 22 (4), 653-668.

Lopez-Sanchez, J.M., Ballester-Berman, J.D., Hajnsek, I., 2011. First results of rice monitoring practices in Spain by means of time series of TerraSAR-X Dual-Pol images. IEEE J. Sel. Top. Appl. Earth Obs. Remote Sens. 4 (2), 412-422.

MAGRAMA, 2013. Ministerio de Agricultura, alimentación y Medio Ambiente. In: <http://www.magrama.gob.es/es/agricultura/temas/producciones-agricolas/ cultivos-herbaceos/arroz/> (accessed on 25.08.13).

Meijide, A., Manca, G., Goded1, I., Magliulo, V., di Tommasi, P., Seufert1, G., Cescatti1, A., 2011. Seasonal trends and environmental controls of methane emissions in a rice paddy field in Northern Italy. Biogeosci. Discuss. 8, 89999032.

Moré, G., Serra, P., Pons, X., 2011. Multitemporal flooding dynamics of rice fields by means of discriminant analysis of radiometrically corrected remote sensing imagery. Int. J. Remote Sens. 32 (7), 1983-2011.

Motohka, T., Nasahara, K.N., Miyata, A., Manos, M., Tsuchida, S., 2009. Evaluation of optical satellite remote sensing for rice paddy phenology in monsoon Asia using a continuous in situ dataset. Int. J. Remote Sens. 30 (17), 4343-4357.

Oguro, Y., Imamoto, C., Suga, Y., Takeuchi, S., 2001. Monitoring of rice field by Landsat-7 ETM+ and Landsat-5 TM data. In: Paper presented at the 22nd Asian Conference on Remote Sensing, vol. 5, p. 9.

Ordoyne, C., Friedl, M.A., 2008. Using MODIS data to characterize seasonal inundation patterns in the Florida Everglades. Remote Sens. Environ. 112 (11), 4107-4119.

Palacios-Orueta, A., Khanna, S., Litago, J., Whiting, M.L., Ustin, S.L., 2006. Assessment of NDVI and NDWI spectral indices using MODIS time series analysis and development of a new spectral index based on MODIS shortwave infrared bands. In: Proceedings of the 1st International Conference of Remote Sensing and Geoinformation Processing. Trier, Germany. <http://ubt, opus. hbz-nrw, de/ volltexte/2006/362/pdf/03-rgldd-session2, pdf.>, pp. 207-209.

Palacios-Orueta, A., Huesca, M., Whiting, M.L., Litago, J., Khanna, S., Garcia, M., Ustin, S.L., 2012. Derivation of phenological metrics by function fitting to time-series of Spectral Shape Indexes AS1 and AS2: Mapping cotton phenological stages using MODIS time series. Remote Sens. Environ. 126, 148-159.

Peng, D., Huete, A.R., Huang, J., Wang, F., Sun, H., 2011. Detection and estimation of mixed paddy rice cropping patterns with MODIS data. Int. J. Appl. Earth Obs. Geoinf. 13 (1), 13-23. 
Pettorelli, N., Vik, J.O., Mysterud, A., Gaillard, J.M., Tucker, C.J., Stenseth, N.C., 2005. Using the satellite-derived NDVI to assess ecological responses to environmental change. Trends Ecol. Evol. 20 (9), 503-510.

Sakamoto, T., Yokozawa, M., Toritani, H., Shibayama, M., Ishitsuka, N., Ohno, H., 2005. A crop phenology detection method using time-series MODIS data. Remote Sens. Environ. 96, 366-374.

Sakamoto, T., Nguyen, N.V., Ohno, H., Ishitsuka, N., Yokozawa, M., 2006. Spatiotemporal distribution of rice phenology and cropping systems in the Mekong Delta with special reference to the seasonal water flow of the Mekong and Bassac rivers. Remote Sens. Environ. 100, 1-16.

Sari, D.K., Ismullah, I.H., Sulasdi, W.N., Harto, A.B., 2010. Detecting rice phenology in paddy fields with complex cropping pattern using time series MODIS data. ITB J. Sci. 42 (2), 91-106.

Setiawan, Y., Rustiadi, E., Yoshino, K., Effendi, H., 2014. Assessing the seasonal dynamics of the Java's Paddy field using MODIS satellite images. ISPRS Int. J. of Geo-Inf. 3 (1), 110-129.

Singh, R.P., Oza, S.R., Pandya, M.R., 2006. Observing long-term changes in rice phenology using NOAA-AVHRR and DMSP-SSM/I Satellite Sensor Measurements in Punjab, India. Current Science (00113891), 91(9)

Son, N.T., Chen, C.F., Chen, C.R., Chang, L.Y., 2013. Satellite-based investigation of flood-affected rice cultivation areas in Chao Phraya River Delta, Thailand. ISPRS J. Photogramm. Remote Sens. 86, 77-88.

Son, N.T., Chen, C.F., Chen, C.R., Duc, H.N., Chang, L.Y., 2014. A phenology-based classification of time-series MODIS data for rice crop monitoring in Mekong Delta, Vietnam. Remote Sens. 6 (1), 135-156.

Tang, L., Zhu, Y., Hannaway, D., Meng, Y., Liu, L., Chen, L., Cao, W., 2009. RiceGrow: a rice growth and productivity model. NJAS-Wageningen J. Life Sci. 57, 83-92.

Torbick, N., Salas, W.A., Hagen, S., Xiao, X., 2011. Monitoring rice agriculture in the Sacramento Valley, USA with multitemporal PALSAR and MODIS imagery. IEEE J. Sel. Top. Appl. Earth Obs. Remote Sens. 4 (2), 451-457.

Ustin, S.L., 2004. Remote sensing for natural resource management and environmental monitoring. American Society for Photogrammetry and Remote Sensing. John Wiley and Sons, USA.
Van Niel, T.G., McVicar, T.R., 2004. Current and potential uses of optical remote sensing in rice-based irrigation systems: a review. Australian J. Agric. Res. 55 (2), 155-185.

Vermote, E.F., Vermeulen, A., 1999. Atmospheric correction algorithm: spectral reflectances (MOD09). ATBD Version, 4

Wang, H., Chen, J., Wu, Z., Lin, H., 2012. Rice heading date retrieval based on multitemporal MODIS data and polynomial fitting. Int. J. Remote Sens. 33 (6), 1905 1916.

Whiting, M.L., Li, L., Ustin, S.L., 2004. Predicting water content using Gaussian model on soil spectra. Remote Sens. Environ. 89 (4), 535-552.

Wu, W.B., Yang, P., Tang, H.J., Zhou, Q.B., Chen, Z.X., Shibasaki, R., 2010. Characterizing spatial patterns of phenology in cropland of China based on remotely sensed data. Agri. Sci. China. 9 (1), 101-112.

Xiao, X., Boles, S., Frolking, S., Salas, W., Moore Iii, B., Li, C., Zhao, R., 2002 Observation of flooding and rice transplanting of paddy rice fields at the site to landscape scales in China using VEGETATION sensor data. Int. J. Remote Sens. 23 (15), 3009-3022.

Xiao, X., Boles, S., Liu, J., Zhuang, D., Frolking, S., Li, C., Moore III, B., 2005. Mapping paddy rice agriculture in southern China using multi-temporal MODIS images. Remote Sens. Environ. 95 (4), 480-492.

Xu, Y., Zhang, J., Yang, L., 2012. Detecting major phenological stages of rice using MODIS-EVI data and Symlet 11 wavelet in Northeast China. Shengtai Xuebao/ Acta Ecologica Sinica 32 (7), 2091-2098.

Zhang, J., Xu, Y., 2012. Detecting Major phenological stages of rice using MODIS-EVI data and symlet11 wavelet in Northeast China. In: Remote Sensing Environment and Transportation Engineering (RSETE), 2012 2nd International Conference on IEEE, pp. 1-4.

Zhang, X., Friedl, M.A., Schaaf, C.B., Strahler, A.H., Hodges, J.C., Gao, F., Huete, A., 2003. Monitoring vegetation phenology using MODIS. Remote Sens. Environ. 84 (3), 471-475. 